\title{
Tratado de la injusticia XX Conferencias Aranguren
}

Treatise of Injustice. XX Aranguren Lectures

\author{
REYES MATE \\ Instituto de Filosofía, CCHS-CSIC
}

\begin{abstract}
Resumen. Se plantea la justicia como respuesta a la injusticia. Es una novedad porque las teorías de la justicia de los antiguos y de los modernos entienden la justicia como un apriori de la injusticia. La prioridad de la injusticia exige el concurso de la memoria. Sin memoria de la injusticia no hay teoría de la justicia. El resultado es una justicia anamnética que se presenta como alternativa a las teorías canónicas, pero amnésicas, de la justicia.
\end{abstract}

Palabras clave: Injusticia, memoria, víctimas, desigualdad.
AbSTRACT. Justice is considered as a reply to injustice. This is a novel idea because both ancient and modern theories understand justice as an apriori to injustice. Placing injustice first requires recourse to memory. Without the memory of injustice there can be no theory of justice. The result is an anamnestic justice which is presented as an alternative to the standard but amnesic theories of justice.

Key words: Injustice, memory, victims, inequality.

Las Conferencias Aranguren no son para nadie unas conferencias más y, para mí, menos. Mi vida académica está totalmente vinculada al Instituto de Filosofía que es quien las convoca. Desde el Gabinete Técnico del Ministro de Educación José María Maravall intervine en la gestación y creación del Instituto. Fui luego el primer presidente del Patronato del Instituto, director del mismo y, hasta hoy, investigador de la casa. Quiero agradecer a los compañeros del Instituto el honor que me han hecho al confiarme estas Conferencias en el vigésimo aniversario de su existencia. No encuentro otra forma de corresponder que entregar lo mejor de lo que disponga y en este momento eso se concreta en repensar el itinerario del libro que tengo entre manos, Tratado de la injusticia*.

* Las XX Conferencias Aranguren tuvieron lugar los días 29 y 30 de marzo. En ese momento el libro Tratado de la injusticia no había aparecido (lo ha hecho en junio). Mantengo el título, común a las Conferencias y al libro, porque aunque tengan por objeto de reflexión la justicia anamnética o memorial, las Conferencias más que un resumen son una segunda reflexión sobre el itinerario del libro. 
Con este tratado o tratamiento de la injusticia lo que pretendo, a contrapelo de lo que se lleva, es considerar a la experiencia de la injusticia como el lugar filosófico de una teoría posible teoría de la justicia.

La justicia es desde luego un tema mayor de la reflexión política. Siempre ha sido así, pero ahora más porque la justicia ha pasado de virtud cardinal a fundamento moral de la sociedad. Ese cambio de lo «bueno» a lo «justo» ha sido saludado como un salto cualitativo pues hemos pasado de una justicia doméstica a otra capaz de plantearse criterios aceptables por todos de lo que es justo o injusto. Las modernas teorías de la justicia, se llamen deliberativas, discursivas o procedimentales, viven en esa euforia cuya capacidad de contagio es indiscutible.

Lo que pretendo es revisar críticamente este planteamiento señalando, en primer lugar, lo que se pierde en el paso de la justicia de los antiguos a la de los modernos y llamando la atención, en segundo lugar, sobre un «equívoco originario» que malicia la calidad de los planteamientos modernos. Me refiero a la confusión entre desigualdad e injusticia. Se las toma por lo mismo cuando no lo son. Las desigualdades, en efecto, son naturales y, las injusticias, históricas; las primeras, atemporales y las segundas, con tiempo; aquéllas, moralmente neutras, y éstas conllevan culpas y responsabilidades.

Esta remisión de la injusticia al tiempo explica la complicidad entre memoria y justicia, tema de la segunda intervención. La memoria está al alza. Se habla por doquier de memoria de las víctimas ya sean del Holocausto, de la Guerra Civil, de la esclavitud, de las colonias, de la conquista... Esta explosión memorial, que tanto asusta a los historiadores, tiene que ver con un desarrollo del concepto filosófico de memoria a lo largo del siglo XX cuyo vértice es la afirmación de que la «memoria es justicia». Esta tesis será expuesta en siete puntos: 1) sin memoria no hay injusticia; 2) la justicia es una memoria determinada de la injusticia; 3 ) la memoria abre expedientes que la ciencia clausura; 4) la memoria permite una actualización crítica de la antigua justicia general; 5) sin memoria la justicia global no es universal; 6) la memoria no es la justicia sino sólo el inicio de un proceso que acaba en la reconciliación; 7) el gesto intelectual de Las Casas como talante adecuado al tratamiento teórico de la justicia.

\section{El olvido de las modernas teorías de la justicia}

1. La justicia siempre ha sido un tema mayor de la reflexión política, aunque ahora más que nunca. Para los antiguos era una virtud cardinal, es decir, una virtud transversal que afecta a los actos que tienen que ver con el otro y que tiene la capacidad de llevar al ser humano a sus máximas cotas de realización. Pero hoy es algo más. Es, según John Rawls, «el fundamento moral de 
la sociedad». La sociedad moderna, democrática y liberal, se legitima en tanto en cuanto se base en principios de justicia.

Para visualizar el cambio entre los antiguos y modernos, se distingue entre «lo bueno» y «lo justo». En el cesto de «lo bueno» se coloca a la justicia de los antiguos, que era una justicia para andar por casa, es decir, una virtud que afectaba a los actos de un determinado proyecto de vida (determinado por la naturaleza humana); en el cesto de «lo justo», empero, se ubican las modernas teorías de la justicia, capaces de hacer propuestas aceptables por todo el mundo y no sólo para los de casa, es decir, capaz de amparar distintos proyectos de vida.

Sin pretender de momento hacer un juicio de valor sobre este celebrado paso o pasaje de lo antiguo a lo moderno, sí procede señalar las diferencias entre una y otra concepción.

1.1. Para los antiguos (pensemos en una tradición que va de Aristóteles a Tomás de Aquino), la justicia es, en primer lugar, una virtud, es decir, un tipo de acción con un recorrido limitado puesto que lo suyo es mediar entre las exigencias de la naturaleza y la realización de su finalidad. En segundo lugar, la importancia del otro. La alteridad. Para ser justos hay que atender al otro, dar al otro lo suyo. Por eso, para Santo Tomás, la justicia es indiferente a los sentimientos o las intenciones del que tiene que reparar. La virtud acaece cuando se satisface lo que se debe al otro. Llega a decir que ni siquiera hay que confundir injusticia con pecado. El pecado exige intencionalidad de hacer el mal; la injusticia tiene lugar aunque se practique con la mejor intención. En tercer lugar, su materialismo. Para que haya justicia tiene que haber reparación integral, ad aequalitatem. La igualdad se refiere a bienes no a personas. La justicia no es del orden del discurso. No debería chocar eso del materialismo aplicado a la teoría tomista de la virtud. El tomista Chenu decía que «el materialismo es la espiritualidad de los pobres».

Señalaría un cuarto aspecto por lo exótico que resulta: hablan de una «justicia general». Relacionamos habitualmente la justicia con la justa distribución del bienes comunes; para los antiguos, eso sería una forma de justicia particular, pero además y previamente está la justicia general que consiste en la construcción del bien común. Este no es el PIB, ni el patrimonio nacional, sino los bienes comunes, es decir, la suma de los bienes que procuran todos y cada uno de los singulares. Para la construcción del bien común, Santo Tomás, por ejemplo, reclama una virtud especial, consistente en ordenar los actos de las otras virtudes, que pueden tener una finalidad particular, hacia el bien común. Para entender la originalidad de esta virtud de la justicia, pensemos un momento en qué consistiría la injusticia contra la justicia general. Una forma de injusticia sería, claro, negarse a pagar impuestos, pero también la privación del talento de cada cual o, mejor, el no desarrollo de lo mejor de cada cual, pues sin ese desarrollo la comunidad queda privada de muchos bienes comunes que podrían redundar en el bien de todos. La justicia general re- 
clama el desarrollo de todos y cada uno de los talentos individuales y, por eso, ninguna injusticia comparable a la frustración del proyecto de vida de cada individuo. La justicia es mucho más que la justicia social.

Por arte de magia ese concepto ha desaparecido. La justicia social es fundamentalmente una justicia distributiva.

1.2. La justicia de los modernos tiene otra lógica porque asume de entrada que hay que impartir justicia en una sociedad plural en la que circulan muchas ideas, legítimas, pero diferentes y opuestas, sobre lo que es justo o injusto. Para que en una sociedad así la justicia tenga sentido, hay que conseguir que los criterios para discernir lo justo o injusto sean entendidos y asumidos libremente por todos. Ya no se puede invocar instancias extrañas a la voluntad - como la naturaleza, la religión o el destino - para fundar la ética.

Esto cambia la naturaleza de la justicia. El primer cambio consiste, como ya he dicho, en pasar de ser virtud a fundamento moral de la política. También, si para los antiguos lo importante era el daño hecho al otro, aquí lo que importa es que nosotros decidamos lo que es justo e injusto. Desplazamiento pues del otro al nosotros. De la alteridad al yo colectivo. La tercera característica diferenciadora se refiere al contenido de la justicia. Para que la justicia sea válida para todos, tiene que ser decidida por todos. Un desplazamiento del contenido, de lo que sea justo o injusto, al procedimiento, esto es, al modo de decidir entre todos, los criterios con lo que juzgar lo justo o injusto. Del materialismo al discurso.

Es un gran cambio. Podíamos preguntarnos si el cambio vale le pena o, al menos, si supone un avance, como defienden los modernos. Quedémonos por el momento con la idea de que la preocupación por la justicia viene de lejos y que ha habido notables mutaciones en su tratamiento.

2. Si proyectáramos una mirada sincrónica, es decir, si aplicáramos la lupa no ya a la historia de las teorías de la justicia, sino a cada momento histórico, descubriríamos una constante duda en su arranque. Es como si ya el punto de partida fuera una encrucijada de caminos que apuntan en direcciones diferentes. Los griegos distinguen entre dike, la justicia para con los demás, connotando la dimensión universalista, «sin acepción de personas», que debe caracterizas a la justicia, y temis que es una justicia con los de casa, más singularizada, más absorbente. Otro tanto ocurre en el mundo hebreo que distingue entre nispat, justicia entre varios que permite la figura de un mediador que tenga en cuenta los intereses de todos y rib, que es la justicia con el otro, sin mediación que distraiga de la demanda del otro. No es lo mismo la preocupación de Platón (la idea de justicia) que la de Aristóteles (la acción justa); ni es lo mismo el punto de partida de Kant (la justicia como deber o ley moral o Imperativo Categórico) que el de Hegel (la recomposición de los desperfectos reales que casusa el delito, la reconciliación entre el criminal y la sociedad). 
En el propio Levinas, es decir, al interior de un mismo pensador, encontramos dos enfoques diferentes, difícilmente compatible: un concepto de justicia absoluta, que siempre tiene lugar entre el otro y yo (la justicia del Autrui), y un tipo de justicia que afecta a muchos y que no permite vestir un santo para desvestir otro, sino tener en cuenta a todos (la justicia del Tiers). Lyotard, por su parte, distingue entre litigio que se refiere a conflictos resolubles porque hay un vínculo comunicacional entre las partes y differendo que se refiere a acontecimientos que no son resolubles consensuadamente porque nada hay de común entre las partes enfrentadas. Las víctimas, por ejemplo, no quieren consensos sino respuestas. El Lager es un lugar del differendo. Agamben tiene la osadía de imaginar al Profesor Apel vagando por un campo a la búsqueda de un musulmán con el que verificar su ética de la comunicación. Como ese muerto viviente que es el musulmán ya ni habla - y el habla es básico para las teorías deliberativas - mejor, dice Agamben, es interrumpir el experimento «porque acabaríamos expulsando al musulmán de la humanidad» (Agamben, 1999, 82).

El prestigioso jurista italiano, Gustavo Zagrebelsky, se pregunta si estas dualidades, con frecuencia auténticas alternativas, no se deben a que siempre hay dos abordajes posibles para el tratamiento de la justicia: uno que pone el acento en la especulación como si fuera el razonamiento el que produjera en su reflexión los contenidos de la justicia. El otro acentúa la experiencia de la injusticia. La justicia, incluso la reflexión teórica de la justicia, sería eminentemente reactiva. La justicia como respuesta o responsabilidad a una experiencia que tendría entidad propia.

3. Estos dos enfoques amparan y explican en buena medida esas dualidades. Si los contenidos de lo justo se derivan del razonamiento, podemos pensar la justicia como un escenario en el que los actores se mueven armónicamente, al son del autor. Pero si el acento se pone en la injusticia, lo justo está como imantado por el polo negativo, sin que pueda atender lo exterior al caso.

Lo que domina en las teorías modernas de la justicia es la estrategia especulativa, mientras que la experiencial es evitada como un exceso moral, difícilmente compatible con la universalidad de la razón.

Las causas de esa preeminencia son complejas y se me escapan. Franz Rosenzweig, que al igual que Heidegger, no tenían empacho someter toda la filosofía occidental, von Jonien bis Hegel, a un juicio sumarísimo, diría que la causa está en su querencia idealista; otros como Levinas o Kolakowski llamarían la atención sobre el hecho que para griegos y alemanes el autos o Selbst es al mismo tiempo el yo y lo mismo, es decir, la identidad es la mismidad, esto es, la negación del otro o de lo otro.

Independientemente de cual sea la explicación de este predominio, hay que tomarse en serio este fenómeno de indecisión, tan pertinaz, so pena de regionalizar la justicia. Después de observar detenidamente este extraño fenó- 
meno, me permito intervenir en el debate, planteando la figura del «equívoco originario» como la causa traumática de esta división constante en el tratamiento de la justicia. El equívoco en cuestión se refiere a que no está claro a qué nos referimos cuando hablamos de justicia: ¿a las injusticias? ¿a las desigualdades? ¿a las dos?

El equívoco viene de que con un mismo término - «injusticia»- estamos significando dos mundos diferentes: el de la injusticia y el de la desigualdad: la desigualdad habla de diferencias sociales que están ahi y que incomodan a la conciencia moral moderna porque nadie se merece ser pobre o vivir en una sociedad con un índice de esperanza de vida inferior a la media o carecer de medios necesarios para desarrollar todos los talentos que uno tiene. La injusticia añade a la desigualdad la culpabilidad o la responsabilidad, no por supuesto en el sentido de que el pobre sea culpable de su pobreza. La culpa se refiere al origen de la desigualdad. Las injusticias no están ahí como los ríos o las montañas, productos del azar, sino que han sido causadas y/o heredadas por el hombre. Por eso va unida a la injusticia el carácter de culpa, en quien la produce, y de responsabilidad, en quien la hereda. Es evidente que también hay un elemento de azar en las desigualdades, pero lo inquietante es que las teorías de la justicia no se detengan ante lo que tienen de voluntariedad las desigualdades, es decir, no se tomen realmente en serio las injusticias.

No es lo mismo una cosa que la otra. Si el tema de la justicia son las desigualdades, entonces quien hace teoría de la justicia o quien la imparte puede ser sujeto de la justicia, puede hacer justicia, es decir, puede comportarse como un juez que enjuicia desde un nivel superior o inocente la existencias de desigualdades. Lo que le liga a las desigualdades es la decisión que tome, la teoría que proponga. Antes de ese momento no hay ninguna relación, por eso el que piensa o actúa puede actuar con la imparcialidad o racionalidad o inocencia de un juez. Ahora bien, si las desigualdades son injusticias, entonces el que piensa la justicia o actúa es parte de la realidad y no puede ser juez ni puede pensar soberanamente la justicia. En este caso la pregunta por la justicia ya no estará guiada por el deber nuestro a sacar al pobre de una situación de miseria que no se merece, sino por el reconocimiento del derecho del pobre a denunciar la sustracción de lo que le pertenece y, por tanto, a interrogarnos sobre nuestra riqueza.

Este es el equívoco originario. Damos por hecho que hablar de desigualdad es lo mismo que hablar de injustica. Interpretamos la justicia como un deber de ayuda al desigual, pero no le fundamos en el derecho que puede tener el pobre sobre lo nuestro, sino en el hecho casi natural, pero intolerable, de que haya seres desiguales.

El equívoco originario nunca ha sido debidamente aclarado, ni conjurado. Hemos afinado mucho en lo que a la equidad e imparcialidad se refiere, pero no hay que olvidar que lo que estas teorías pretenden es la elaboración de criterios justos con lo que tratar las desigualdades existentes. Lo que no se divi- 
sa en el horizonte es un tratamiento moral de la genealogía de la desigualdad, es decir, damos por hecho que no hay causalidad histórica ni responsabilidad humana en la aparición de la desigualdad.

4. Decía que el paso de lo «bueno» a lo «justo» supuso un gran cambio en los contenidos que también fue celebrado como un gran avance moral puesto que la justicia - y no el poder o el éxito o la competitividad- era erigida en el fundamento moral de la sociedad.

Aclaremos que el cambio era obligado porque la Ilustración introducía en la historia un tipo de sujeto que no podía tolerar los límites antropológicos que conllevaba la filosofía de la virtud, a saber, las exigencias de una naturaleza y la voluntad concordista de la virtud (aquello de in medio virtus). El acto virtuoso se debe, por un lado, a las exigencias impuestas por la naturaleza y, por otro, se inscribe en una concepción del mundo que asocia bien a equilibrio y mal a conflicto.

El sujeto moderno, sin embargo, está construido sobre el concepto de autonomía, de libertad, de ahí que cualquier figura política o moral tenga que legitimarse como un producto de la libertad humana.

Esto también afecta a la justicia que tiene que ser pensada desde la autonomía del sujeto, sin que pueda entonces escaparse al «politeísmo de los valores» que acompaña fatalmente a esa misma autonomía moderna. Una vez reconocida la prioridad de la autonomía del sujeto es inevitable que cada cual se haga una idea de lo justo en función de sus ideologías o visiones del mundo: para un marxista, la justicia está en función de sociedad sin clases; para un nacionalista, en función de la idea de pueblo. Que el valor sea el pueblo o la sociedad sin clases, es una decisión imposible de demostrar racionalmente.

Son opciones distintas que no cabe desestimar o jerarquizar. Sobre ese politeísmo sólo cabe la mirada liberal, que diría van Parijs. Una mirada liberal «es una concepción que se prohíbe cualquier jerarquización de las diferentes concepciones de la vida buena que se pueda encontrar en la sociedad o, al menos, que otorga un respeto igual a todas las que, entre ellas, son compatibles con el respeto del otro» (van Parijs, 1992, 197). El liberalismo en cuestión se niega a establecer un ranking de calidad entre las distintas teorías de la justicia. Todas, dicen, merecen el mismo respeto porque emanan de la autonomía del sujeto y no hay por qué entrar en sus contenidos. Tan respetable es la idea de justicia de un utilitarista que acepta que el bien de muchos puede acarrear la infelicidad de unos pocos, como la del starec Zosima que se declara culpable de cualquier infelicidad porque la tarea del justo es evitar cualquier mal o como la de Robespierre quien desde lo alto de su amor por la república traduce justicia por ajusticiamiento de todo enemigo potencial de la misma. Si Max Weber crea la figura del «politeísmo de los valores» como consecuencia del fracaso de la razón «carismática» o universal es para dar a entender que no hay manera de jerarquizar racionalmente entre los susodi- 
chos dioses. No hay manera de demostrar racionalmente la superioridad de un valor sobre otro.

La mirada liberal o el politeísmo de los valores tienen el inconveniente, sin embargo, de no poder responder a la exigencia de universalidad propia de la ética en general y de la justicia en particular. Esto es mortal para la justicia pues de poco serviría una teoría de la justicia que no dijera nada al otro o del otro.

Todo esto se lo saben muy bien los modernos teóricos de la justicia, de ahí la necesidad de plantearse el tema de la justicia, de lo justo, a un nivel superior al de esas teorías «particularistas» tan lastradas por sus prejuicios ideológicos. Ese nivel es el de la reconciliación entre autonomía del sujeto y universalidad de sus propuestas.

El modelo es el Imperativo Categórico kantiano: «actúa sólo según una máxima que puedas querer, al mismo tiempo, que sea ley universal», es decir, que será bueno aquello que uno estima que es bueno para sí y para todos.

Sobre la grandeza de este planteamiento hay mucho escrito; sobre sus límites también. El neokantiano Hermann Cohen ya llamó la atención sobre lo problemático que resulta el hecho de que fuera uno mismo el que salvara la universalidad de la máxima al pensar por los demás. Soy yo en efecto el que tiene que pensar que lo que es bueno para mi también lo es para los demás. Mal asunto. Cohen propuso una salida que va a hacer fortuna, aunque nadie se remita a él. Propuso sindicar la decisión: que los demás dijeran lo que pensaban que era bueno y que la decisión fuera de todos. Como bien sabemos esta corrección a Kant fue lo que le llevó a hablar de «socialismo ético».

Es una buena pista pero poco elaborada porque, si se ve cómo superar el autismo kantiano, convocando a los demás, no se ve cómo compaginar las distintas voluntades en el caso probable de que piensen distinto. No convendría en esto confundir universalidad con mayorías. La justicia no puede ser el resultado de una votación democrática.

De esto son conscientes contemporáneos como Rawls y Habermas cuando se plantean la universalidad de lo justo en una sociedad moderna necesariamente plural porque habitada por el politeísmo de los valores.

A la ruda idea de Cohen proponen un modelo de justicia en el que cada cual intervenga autónomamente, pero en condiciones de igualdad, con el objetivo de de decidir normas consentidas por todos. No es tarea fácil pues la decisión autónoma no predispone al consenso, de ahí la cláusula de imparcialidad que conlleva limitar esa autonomía, haciendo abstracción de algo tan propio como los «intereses comprensivos» que uno lleva puestos.

Como eso no es lo que se lleva, es decir, como la vida real funcionada de otra manera, proponen someter al ser humano a un experimento: crear la ficción de un «estado originario», es decir, someter a ese sujeto real egoísta y lleno de prejuicios a la presión de un estado en el que se comporte como un individuo racional al estado puro. 
Eso del «estado originario» tiene antecedentes. Rousseau, por ejemplo, también propone la ficción de un «estado natural» para ver cómo era y se comportaba «el buen salvaje». El «estado originario» no es el del «buen salvaje» sino el del «racional puro». La diferencia es que observando al buen salvaje lo que Rousseau pretende es ver lo que hemos perdido al pasar al estado social, mientras que al colocar Rawls al hombre en el «estado originario» lo que pretende es rescatar lo que caracteriza al ser social. El «estado natural» de Rousseau es una pérdida; el «estado originario» de Rawls es una revelación.

Estamos pues ante dos experimentos. En el laboratorio del estadounidense lo que se va a investigar es lo que decidiría un ser humano, si tuviera que hacerlo, abstrayendo de sus «intereses comprensivos» pero guiado, eso sí, de los intereses propios de un individuo racional al estado puro. Se trata de saber lo que decidiríamos en el «estado originario», tocados para la ocasión con el «velo de la ignorancia» y vestido cada cual de «egoísta racional». El experimento arroja un gran resultado, a saber, dos grandes principios. Decidiríamos o estaríamos de acuerdo en a) que la libertad es intocable hasta el punto que ninguna estrategia de reparto o reparación puede cuestionarla lo más mínimo. Prioridad de le libertad. Y b) que hay que tratar mejor a los peor tratados por la vida. Principio de la diferencia o de la comprensión.

En el laboratorio del alemán los resultados son más modestos. No consigue producir principios o leyes de la justicia. Se queda en el procedimiento, en el modo de tomar decisiones justas sobre los asuntos que se vayan poniendo sobre la mesa. Lo que descubre es que para dar con un modo racional de tomar decisiones justas hay, en primer lugar, que convocar a toda la humanidad y colocarles, en un segundo momento, a todos los seres humanos en condiciones semejantes, es decir, crear las condiciones necesarias para que todos se sientan igualmente libres a la hora de decidir, liberados, por tanto, de las presiones que pudieran mermar su libertad en la decisión. Finalmente, comprometerles a que decidan en razón del argumento más convincente.

La justicia no consiste en luchar contra la tiranía o las torturas, ni siquiera en decir si torturar es justo o injusto. La justicia consiste en decir cómo decidir sabiamente si este caso es justo o injusto... Con razón Juan Carlos Velasco dice que en Habermas no hay un corpus sobre la justicia; sólo hay un método para detectar casos de injusticia o un procedimiento para determinar cómo tomar una decisión justa. Pero que no se le pida a esa concepción de lo justo que se ocupe de o que diga algo sobre «los grandes males de nuestra existencia: el hambre y la miseria en el Tercer Mundo; las torturas y la violación de los Derechos Humanos en Estados sin derecho; el creciente desempleo o la injusta distribución de la riqueza en los países industrializado; la carrera armamentística y la amenaza nuclear» (Habermas, 1986, 32). Nada puede decir su ética sobre estos asuntos, por muy frustrante que resulte, añade Habermas. Que lo decidan los ciudadanos, armados, eso sí, de los criterios que él proporciona. 
La reducción de la justicia a mero procedimiento no satisface, sin embargo, al propio autor. Habermas es, en efecto, un pensador que propone un rígido sistema filosófico que le prohíbe, de acuerdo con su lógica, emitir un juicio moral sobre las miserias del mundo, mientras que, por otro, ejerce de intelectual activo que toma parte en los conflictos de su tiempo - defendiendo la singularidad de Auschwitz en el debate de los historiadores, pidiendo una moratoria en la investigación científica por los riesgos de la manipulación genética o discutiendo con el mismísimo Papa de Roma el lugar de la religión en una sociedad postsecular - sin esperar al Día del Juicio para saber qué piensa la comunidad de comunicaciones sobre estos candentes asuntos.

Por eso se pregunta si de verdad podemos hablar de «justicia universal, de rectitud normativa, de punto de vista moral, etc., sin tener en cuenta la visión de una vida buena» (Habermas, 1991a, 117), es decir, si podemos reducir lo justo a la búsqueda de criterios universales o también hay que tener en cuenta los destinos individuales y los problemas concretos.

La insólita pregunta le obliga a revisar su teoría de lo justo que debería, a partir de ahora, asentarse sobre dos patas: por un lado, el ya conocido concepto de justicia, atento a la igualdad en la libertad de todos y cada uno de los participantes en esa mesa de negociación que es el discurso y, por otro, el nuevo concepto de solidaridad que se hace cargo de la situación de los individuos concretos en posición desventajosa y que distan de estar en esas condiciones ideales de participación que exige la justicia. La solidaridad se hace cargo de esas existencias derrotadas, heridas o frustradas y se empeña en que se logren.

Entiéndase bien: esta sensibilidad social de la justicia habermasiana no significa que la justicia tenga que ocuparse de las miserias del mundo, perdiendo de golpe esa dimensión universal tan duramente conquistada en su teoría discursiva. «Que no se confunda esta atención al singular con lo que se ha dado en llamar cuidado del particular» (Fürsorge) (Habermas, 1991, 198). Esta aclaración es fundamental para el tema que nos ocupa pues Habermas no puede ni quiere subsumir bajo la reflexión sobre la justicia exigencias morales ligadas a destinos absolutamente singulares. No quiere verse contaminado por el complejo significativo del término Fürsorge. El otro en cuanto otro no aporta nada a una concepción de la justicia. Lo aporta en cuanto es igual, no en cuanto es diferente. El otro sólo cae bajo la consideración de la justicia en tanto en cuanto se integra en la comunidad de iguales. Es el engranaje de la comunidad, alterado cuando una de sus piezas no funciona bien, lo que le lleva a interesarse por el destino individual, pero no para detenerse en su singularidad sino para llevarle al redil de la igualdad. No se habla del otro como diferente sino del otro como semejante, como miembro de la comunidad, como uno más.

Dos pensadores tan opuestos como Habermas y Derrida coinciden, sin embargo, en la afirmación de que Fürsorge y Diskurs son incompatibles, aun- 
que por razones radicalmente opuestas. Para Habermas la atención al otro que exige la ética del cuidado o de la alteridad no tiene nivel teórico, carece de la ambición universalista propio de una ética de lo «justo». Para Derrida, por el contrario, esas éticas procedimentales reducen la justicia a la reciprocidad dejando fuera de consideración una serie de diferencias que no admiten simetría alguna, que sí son contempladas por una ética basada en la amistad y en la fraternidad, debidamente «deconstruidas».

5. Estas teorías, llamadas procedimentales, han dado la vuelta al mundo y se han impuesto en todo el orbe. Sus ecos van de la selva Lacandona a Berlín o Roma pasando por Barranquilla o Marrakech. En un momento u otro todos hemos hablado de teorías discursivas, deliberativas, del consenso, del discurso, del procedimiento. Y si no hemos hablado de ello lo hemos tenido que oír. Dominio pues planetario del procedimentalismo.

Por supuesto que no le han faltado críticos (entre nosotros Javier Muguerza planteando «la alternativa de la disidencia»). Recordemos que este procedimentalismo aparece en el horizonte kantiano con la voluntad de dar consistencia a la intuición de Cohen, de ahí la idea de someter la idea neokantiana a un experimento. Pero es un extraño experimento ya que no hay experimentación, no hay muestras representativas sometidas a experimento. Lo que hay es imaginación, aunque aquí se quiera disimular su carácter ficcional con la palabra «contrafáctica». Los únicos que experimentan y lo hacen en nombre de todos, de toda la humanidad en el caso de Habermas, son Rawls y Habermas.

De entre las críticas quisiera subrayar, por su agudeza, dos que vienen del campo hispanohablante. La primera es de Carlos S. Nino, el eminente filósofo argentino del derecho. Se pone tanto el acento en la libertad, dice, que la justicia acaba siendo «un reparto igualitario de la libertad» (Nino, 1996, 478). Lo decisivo en esta justicia es la decisión libre, la igualdad en la libertad a la hora de decidir. Pero la justicia — cabe comentar por nuestra parte - siempre había sido un reparto equitativo del pan, de bienes materiales. Pan y libertad no son incompatibles, por supuesto. Van juntos. Pero con un orden. Dice Bloch: «el estómago es la primera lamparilla en la que hay que echar aceite» $\mathrm{y}$ «el hambre y el amor ponen al mundo en movimiento». Tienen que ir juntos pero en ese orden: primero el pan.

Ahora bien, si la justicia se reduce a un problema de libertad, habremos despolitizado la política y, sobretodo, abaratado la democracia. Desde 1989 se han creado 22 nuevos Estados y todos son democracias liberales. Más aún, lo son no en contra sino con el beneplácito de los países más ricos y poderosos del mundo. Ése es el hecho sorprendente. Hasta hace poco tiempo, los Estados poderosos recelaban de las nuevas democracia (pensemos en la enemiga de Estados Unidos respecto a la democratización en los países pobres, en los años cincuenta y sesenta). Ahora las apoyan a bombo y platillo. Quizá se entienda el cambio de actitud si examinamos lo político de las nuevas de- 
mocracias liberales y lo comparamos con las antiguas democracias. Durante mucho tiempo, en efecto, la democracia era una exigencia fuerte porque al concepto de libertad en política iba unido la idea de un reparto del patrimonio nacional entre todos los miembros de la sociedad democrática. Para decirlo breve y pronto: en esas democracias la idea de libertad iba unida a la de la justicia. Las nuevas democracias liberales ya no tienen ese problema desde el momento en que hasta la justicia es un asunto de libertad. «El mundo tendrá hoy» — decía el entonces Director General de la Unesco, Mayor Zaragoza-, «más libertad pero menos democracia». La contaminación del liberalismo es tal que hasta cuando la izquierda habla de igualdad sobreentiende que es «igualdad en la libertad», olvidando que históricamente la igualdad se pensaba en relación a la desigualdad social.

El mexicano Luis Villoro, el autor hispanohablante más penetrante en temas de justicia, hace el segundo apunte crítico. Dice que esas teorías de la justicia, basadas en el consenso racional logrado por sujetos iguales, pueden funcionar en sociedades desarrolladas donde ya hay de hecho un nivel aceptable de distribución de riquezas. En sociedades con profundas desigualdades sociales, sin embargo, ese consenso es impensable, más aún, inimaginable, y sólo cabe entender la justicia como respuesta a la injusticia.

Crítica pues a la contaminación liberal, en el caso de Nino, y a la imposición en los países pobres de un modelo pensado en, por y para los países ricos, en el caso de Villoro.

Pero en vez de proseguir ese doble trazado crítico, prefiero concentrarme en las críticas que han salido de sus propias filas, más en concreto, las críticas que hace Amartya Sen, Premio Nobel de Economía, autor de «Ideas de la Justicia», libro dedicado precisamente a John Rawls ${ }^{1}$.

5.1. Dice Amartya Sen: «La pregunta por la sociedad justa no es un buen punto es partida para una teoría útil de la justicia. A eso hay que añadir la concusión adicional de que puede no ser tampoco un buen punto de llegada» (Sen, 2010, 135). Sen cuestiona el punto de partida y el de llegada de Rawls, es decir, critica todo el dibujo de la teoría rawlsiana.

Cuestiona, en primer lugar, el punto de partida. Dice Sen muy solemnemente: «tengo que expresar mi considerable escepticismo sobre la muy específica tesis de Rawls sobre la elección única, en la posición original, de un particular conjunto de principios para las justas instituciones que se requieren para una sociedad justa» (Sen, 2010, 86). Lo que no ve claro es que el experimento funcione, es decir, que de la posición original emergerían esos principios (Sen 2010,139). No ve que los seres humanos, sometidos al experimento del estado originario, llegaran a la misma conclusión. Pone el ejemplo de tres

1 Una ponderada y empática exposición del pensamiento de Sen es la de Francisco Álvarez, «La propuesta inmanentista de Amartya Sen para la justicia global», en Isegoría, núm. 43 (julio-diciembre 2010), 617-630. 
niños que tienen que decidir quien se queda con la única flauta. Anna alega que es ella porque es quien la sabe tocar; Bob que él porque es el más pobre y no tiene juguetes propios; y Carla que ella porque es quien la ha fabricado. Son todas razones válidas pero ¿a quién dársela? ¿quién tiene razón? Para un utilitarista, Anna porque es quien más uso y provecho y disfrute la puede sacar; para un igualitarista, Bob porque es quien menos tiene; para un marxista, Carla, por aquello de que «la tierra es para quien la trabaja». Cada uno tiene una razón «imparcial» pero que no es única. Cada familia argumentará que tiene la razón única, pero como hay distintas familias, habrá distintas razones (Sen, 2010, 47).

El experimento está mal diseñado. Dice éste que para conseguir qué sea lo justo, para construir una justicia como equidad, el secreto es la imparcialidad. Si los actores son imparciales pueden dar con criterios equitativos. Según Sen, Rawls no lo consigue, no consigue que los actores sean imparciales. ¿Que por qué? por dos razones. En primer lugar, porque no todos los afectados por las decisiones pueden decidir. No olvidemos que los participantes en el experimento del estado originario no es toda la humanidad sino un grupo humano, más exactamente «los que nacen en la sociedad en la que viven» ${ }^{2}$. No nos escapamos de la «tierra y sangre» que diría Carl Schmitt. Participan los nuestros, pero ¿qué pasa, se pregunta Sen, con los emigrantes? Estaríamos ante una «negligencia excluyente» a la que habría que sumar una «incoherencia incluyente» (Sen, 2010, 168). Se refiere a que los buenos principios del «estado originario» podrían provocar un efecto llamada en habitantes de otros lugares que tendría, una vez situados en el país de acogida, someterse a decisiones en las que ellos no intervienen. Y, además, porque los que deciden no lo hacen libremente. Podemos entender que los que deciden dentro del grupo convocado lo hagan imparcialmente, sin buscar el interés personal. Pero lo que no está asegurado es que a la hora de decidir estén liberados de los tópicos o prejuicios que son comunes a un colectivo. Serían víctimas de un «parroquialismo procedimental». Esto explica la importancia que da Sen a la figura del «observador imparcial» que él toma de Smith, pero que también encontramos en Simmel («el forastero»), en Mannheim («die freischwebende Intelligenz», término acuñado por Alfred Weber) ${ }^{3}$. Ese observador que viene

2 «La justicia como equidad recupera y reformula la doctrina del contrato social... los términos equitativos de la cooperación social tienen que entenderse como si fueran acordados por quienes están comprometidos con ella, esto es, por ciudadanos libres e iguales que nacen en la sociedad en la que viven», J. Rawls, El liberalismo político, 53.

3 Eran, como acabamos de decir, forasteros. Simmel, en su Sociología. Estudios sobre las formas de socialización (1908) analiza la figura del extranjero que «llega hoy y se queda mañana». Es un emigrante que entra en contacto con un grupo local o nacional ya constituido. No pertenecía antes al círculo y nunca pertenecerá del todo. De él toma mucho y aporta algo que el grupo nunca tendría. Hay una identificación parcial. Está como enfrente y fuera. Su tendencia a la percepción objetiva surge del hecho de no encontrarse ligado por ninguna consideración que pudiera ser «un prejuicio para la percepción, comprensión y estimación de los objetivos». 
de fuera posee una mirada inquietante, como Clint Eastwood en «Infierno de Cobardes», que conmueve los tópicos y tabúes de la comunidad. Hay que distinguir bien entre una imparcialidad cerrada, como la de Rawls, y otra abierta, como la que Sen propone.

5.2. Sen también cuestiona el punto de llegada porque no es de utilidad alguna. No sirve a la causa de la justicia. Incluso en el que caso de que Rawls lograra su objetivo, es decir, lograra atrapar la esencia de lo justo, definir la justicia transcendental, «la solución única», la justicia al estado puro, ¿de qué serviría? ¿serviría para hacer justicia en un mundo injusto? Trae un ejemplo de la historia del arte para explicar la inutilidad del modelo. Imaginemos que La Gioconda sea el ideal de la pintura; ¿serviría eso para decir si es mejor un Picasso que un van Gogh?

Por eso mismo el objetivo que persigue Rawls no es un buen punto de llegada. Lo que mueve a cuantos se ocupan de la justicia, incluso al mismo Rawls, es la mejora de la situación. La causa de la justicia es la lucha contra la injusticia. Para lograr este objetivo el planteamiento tiene que ser otro.

El arma adecuada para esa lucha es una «teoría de la elección social», inspirada en la tradición ilustrada «comparatista» (la de Smith, Condorcet, Marx y no la trascendental o contractualista de Kant y Rousseau) que: a) pone el énfasis en lo comparativo y no sólo en lo trascendental. La razón práctica de esta teoría se centra y concentra en cómo elegir bien entre opciones posibles y no en la especulación de la razón teórica sobre la justicia ideal; b) que reconocer que hay pluralidad de principios y que pueden rivalizar entre sí, como en el caso de las niñas; c) que acepta soluciones parciales o medidas concretas que aminoren la injusticia; d) que no deja atrapar por el provincianismo del grupo dando cabida en la decisión a otras voces; e) que se tome en serio el debate público sobre la mejor decisión sin fiarse de experimentos contrafácticos (Sen, 2010, 136 y ss.).

Su modelo de justicia se inspira en su tradición india, más en concreto, en el joven Gautama — Buda - que abandona su palacio al pie de los Himala-

La presencia y la distancia le proporcionan una vis aestimativa, cercana a la «objetividad», es decir, a la mirada desinteresada. Así lo describe: «como el extranjero no se encuentra unido radicalmente con las partes del grupo o con sus tendencias particulares, tiene frente a todas esas manifestaciones la actitud peculiar de lo «objetivo», que no es meramente desvío y falta de interés, sino que constituye una mezcla sui generis de lejanía y proximidad, de indiferencia e interés» (102). Años más tarde, otro extranjero, Karl Mannheim, desarrollaba la misma idea bajo la figura de la freischwebende Intelligenz (inteligencia libremente flotante. Término acuñado por Alfred Weber). Inteligencias libres, liberadas de todo dogmatismo, dispuestas a obedecer la realidad por encima de cualquier compromiso con la tribu intelectual dominante. El forastero dispone de la perspectiva más desprendida e impersonal. Y, de entre ellos, es el intelectual quien más lejos puede llevar esa amplitud de miras. Éste, en efecto, no está implicado en los procesos productivos y está obligado a trabajar contando con los demás. «Esta peculiar situación de independencia sin aislamiento maximiza la probabilidad de que, en el curso normal y rutinario de su trabajo, sea el intelectual quien haga los mayores y más imaginativos esfuerzos para obtener una comprensión intercontextual» (279). Cf. Gil Villegas, F., 1996, Los profetas y el Mesías, FCE, México, 102 y ss., 279. 
yas, movido por las muertes, enfermedades y discapacidades a su alrededor. La preocupación por la justicia debe centrarse «en la eliminación de las injusticias manifiesta en lugar de concentrarse en la búsqueda incesante de la sociedad perfectamente justa» (Sen, 2010, 289).

Este es un cambio de ciento ochenta grados. Desde luego, hay poderosas razones para plantear la justicia como respuesta a la injusticia. Está, por un lado, el sentido común que nos dice que la preocupación por la justicia aparece como respuesta a situaciones inaceptables. Y, en segundo lugar, porque hay más de sentido de la justicia en el grito existencial de un «no hay derecho» que en lo que contengan todas las leyes juntas imaginables. Cuando uno expresa su indignación ante una injusticia manifiesta, gritando ¡no hay derecho!, no está queriendo decir sólo que allí no se aplica la ley o se lo aplica mal, sino, más bien que no hay ley que ampare esa injusticia. No hay amparo legal, ni referente moral al que acogerse porque todos están del otro lado, y, sin embargo, sabe que estamos ante una injusticia. En ese grito no sólo se dice que estamos ante una situación que no respeta las leyes existentes sino ante un momento de lo justo no recogido en las leyes, ni en las costumbres, ni en la sensibilidad general, ni en las especulaciones sobre la justicia.

Pensemos en la esclavitud, vigente en Occidente hasta finales del siglo pasado. Era legal, casaba con la sensibilidad general, estaba legitimada filosófica y teológicamente. Todas las «divisiones» de la justicia estaban de su parte. Cuando surgía un Espartaco que se rebelaba al grito de ¡no hay derecho! había más «justo» en ese grito de indignación que en las divisiones culturales de la justicia.

Esa indignación es la que guía la investigación del joven periodista de la Gaceta Renana, Karl Marx, cuando investiga una nueva ley prusiana sobre el robo de en los bosques. El Estado prusiano considera, contra el derecho consuetudinario, que el uso por los pobres de la leña caída en un bosque, es un robo. Para Marx la nueva ley pretende abolir el derecho imprescriptible de los pobres al bien común ofrecido por la naturaleza. Es en la ley donde ¡no hay derecho! Es la ley la que es injusta y, lo justo, lo que está contra la ley. El robo es la propiedad protegida por la ley (Bensaïd, 2007, 18).

5.3. Con ser sólidas las críticas de Amartya Sen quisiera al menos dejar constancia de una línea crítica, mucho menos habitual, que ha emergido con la publicación de un texto teológico de un joven Rawls. En la edición alemana y francesa aparece un epílogo de Habermas que es del mayor interés. Tanto Habermas como los autores de los dos estudios introductorios señalan la relación entre el esquema teológico del joven Rawls y la teoría de la justicia de un Rawls adulto y ya descreído ${ }^{4}$.

${ }^{4}$ Habermas, 2010, «La vie bonne, une expression detestable. La signification de l'éthique religieuse du jeune Rawls pour sa théorie politique» en Rawls, J., 2010, Le péché et la foi. Ecrits sur la religion, Hermann, Paris, 351-377. 
El escrito «El pecado y la fe» desarrolla una ética dialógica en la que las relaciones interpersonales entre «yo» $\mathrm{y}$ «tu» confirman una comunidad de iguales. Lo propio de este esquema es que la comunidad no es el producto de las meras relaciones interpersonales sino que esas relaciones se inscriben en un horizonte trascedental que religa a de cada persona con la divinidad. El esquema trinitario - personas diferentes pero iguales en la divinidad - se traduce en una comunidad de personas diferentes y hasta desiguales pero capaces de una relación equitativa gracias a un supuesto transcendental (la filiación divina). Ese supuesto trascendental es el que permite pensar las relaciones humanas reales - dominadas por el pecado del «orgullo», es decir, de la dominación y de la desigualdad - como capaces de conformar una comunidad de iguales ${ }^{5}$.

Para Habermas, el Rawls maduro seculariza el supuesto teológico transcendental en uno filosófico («el estado originario») y que se resuelve en el reconocimiento de que sin ese supuesto sería imposible sobresaltarse por las desigualdades del mundo.

Lo que a mí me interesa subrayar es el hecho de que a su Teoría de la Justicia subyace una teología política muy determinada. El la llama «bíblica», huyendo de versiones «aristotélicas»: ¿no dice acaso que «una onza de la Biblia pesa más que un libro - incluso más que una tonelada de libros- de Aristóteles»? (Rawls, 2010, 144), pero es una Biblia muy luterana, muy liberal, es decir, leída desde la preocupación moderna por la igualdad en la libertad. Pero hay otras teologías políticas. Remito al debate entre el filósofo radical judío, Jacob Taubes, y el filonazi Carl Schmitt, para recordar el abanico de la teología política.

6. Sen acaba donde empezó Rawls. La lucha contra el desorden existente, las desigualdades sociales, la pobreza, la miseria, era también la motivación de partida de Rawls y de Habemas. Rawls empieza su Teoría de la justicia diciendo que lo que desencadena su reflexión teórica es el hecho de que «la sociedades existentes rara vez están bien ordenadas» (Rawls, 1978, 20), es decir, es el desorden existente. Otro tanto ocurre con Habermas para quien el ingente argumentario de la «razón comunicativa», que él trae a colación, «sería la respuesta filosófica a la experiencia de la vulnerabilidad del ser humano» (Habermas 1986, 21) ${ }^{6}$. Philippe van Parijs apunta en la misma dirección al decir que la justicia entra en juego cuando se dan «las circunstancias de la justicia» (van Parijs, 1992, 213), a saber, la escasez de objetos y la desigualdad de sujetos. Si todo fuera bien y hubiera de sobra y todo el mundo se sintiera igual, no habría lugar para cavilar sobre la justicia porque no habría

5 Para Rawls el modelo de pecado es el de Adam «que es la destrucción de la comunidad para con Dios» (Rawls, 2010, 98). Esa ruptura tiene que ver con el «orgullo» que connota dominación o desigualdad.

${ }^{6}$ La tarea de la «ética discursiva» consiste en «atender las necesidades de una vulnerable existencia humana», dice Habermas en «Treffen Hegels Einwände gegen Kant auch auf die Diskursethik zu?», cf. Kuhlemann, W. (Hrsg), 1986, Moralität und Sittlichkeit, Suhrkamp, 21. 
desigualdades o injusticias que resolver. Esas circunstancias que provocan la reflexión son en realidad las desigualdades e injusticias.

Si ese es el punto de partida, la pregunta es ¿por qué le pierde de vista cuando se ponen manos a la obra? ¿Por qué, para elaborar una teoría de lo justo, hay que hacer abstracción de la miserable situación real e imaginarse un estado originario de bienaventurados o una comunidad ideal de diálogo sobre la que Javier Muguerza ironizaba, con razón, llamándola «la comunión de los santos»? Esa operación de abstracción que tiene lugar en el experimento es de la mayor importancia. Se pide a todo el mundo que no se fije en lo que le pasa. Se pide al rico y al poderoso que no hagan valer su situación de privilegio y, al pobre, que no se lamente de sus miserias. Altura de miras. Pero esa abstracción es muy asimétrica: para el rico es garantía de que no se va a cuestionar su riqueza; para el pobre, que no va a poder hacer valer las causas de su miseria. Pero ¿por qué hacer abstracción de la realidad en vez de atenerse a ella? ${ }^{7}$.

Si Rawls fuera Aristotélico podría invocar en su favor la tesis de que la injusticia es carencia de justicia y de ser. Es un no-ser como dice Aristóteles en su Metafísica. Y del no-ser, añade, no hay ciencia. Claro que Rawls no es aristotélico. Acabamos de ver con qué orgullo predicaba que había más sabiduría en un versículo de la Biblia que en todo Aristóteles.

Pero no hay que ir tan lejos. La respuesta está en el equívoco originario, es decir, en reducir la injusticia a desigualdad. Rawls no puede hablar de injusticias, ni puede tomarse en serio las experiencias de injusticia, ni reconocer significación propia a la injusticia. ¿Que por qué? pues porque para reconocer entidad a la pregunta habría que reconocer que hubiera alguien al que pedir cuentas porque tiene que ver con el origen de los hechos y que hubiera algo de lo que dar cuenta porque son sus hechos o ha heredado sus consecuencias.

Pero Rawls no está dispuesto a adentrarse por esos andurriales. El está dispuesto a dejarse interpelar por la miseria del mundo pero sólo en tanto en cuanto la miseria hiere a su sensibilidad moral, no porque los hechos tengan algo que decirle. Para neutralizar la capacidad interpelante de los hechos, declara a las desigualdades existentes, cosas de la fortuna.

La fortuna puede tomar la forma de nacimiento, naturaleza o destino. Ahora bien, lo que haga la naturaleza «no es justo ni injusto, como tampoco es injusto que las personas nazcan en una determinada posición social. Esos

7 Este planteamiento abstracto de las desigualdades tiene que ver con la posición de Rawls sobre el mérito que detesta. El rico tiene que saber que su riqueza es inmerecida, producto del azar y, por tanto, un don. Se ve la buena intención o el interés de Rawls por minar cualquier causa del «orgullo» que coloque a alguien por encima de uno. Pero ese planteamiento tiene un efecto perverso porque si lo que tiene el rico es un don, ¿qué decir si lo que hereda es producto del robo? ¿tendrá que dar gracias o dar cuenta? Tampoco es de mucho consuelo decir que el pobre no se merece su pobreza. Está bien para empezar pero siempre y cuando eso no signifique renuncia a exigir sus derechos primarios sobre la tierra o a plantear su pobreza como empobrecimiento. 
son hechos meramente naturales. Lo que puede ser justo o injusto es el modo en que las instituciones actúan respecto a estos hechos» (Rawls, 1978, 124-5). Nada que decir, por ejemplo, sobre la fortuna de los hijos de Gaddafi. $\mathrm{Si}$ las desigualdades son naturales, son neutras moralmente. Dice McIntyre que la justicia en Rawls se parece a una isla desierta a la que llegan unos náufragos que se encuentran con otros también llegados por casualidad. Nadie tiene la culpa de las desgracias que cada uno ha vivido. La justicia se centra en el presente, en resolver los problemas que ahora surgen, sin preocuparse de lo que ha llevado a ese momento, ni de cómo ha llegado cada cual. La justicia se concentra «en las reglas que salvaguarden máximamente a cada uno en tal situación» (McIntyre, 1987, 307).

La moralidad está del lado de nuestras convicciones, no de las exigencias o derechos derivados de los hechos.

Aunque en el desarrollo de esos condicionantes naturales juegue un papel la libertad de cada cual, Rawls, que no da una puntada sin hilo, tiene interés en considerarles en su conjunto como «arbitrariedades de la fortuna» (van Parijs, 1992, 174). Nada podemos pues contra el origen de las desigualdades puesto que escapan a la voluntad del hombre. Ahora bien, como ese desigual punto de partida va a condicionar poderosamente el desarrollo de cada cual, ahí sí podemos intervenir con el fin de evitar que las desigualdades de origen se mantengan o reproduzcan. Por eso añade que lo que puede ser justo o injusto es cómo respondan las instituciones.

Podemos intervenir porque nada impide que con un buen plan de becas un niño dotado, pero pobre, pueda ser ingeniero, igual que un hijo de buena familia. Y también podemos conseguir, mediante un buen plan de apoyo, que un alumno menos dotado apruebe todos los estudios obligatorios. Podemos pues encauzar las desigualdades creadas por el destino. Pero ¿por qué habría que hacerlo? Por un prejuicio moral moderno que nos lleva a tratar igual a todo el mundo. Para el hombre moderno, que vive al amparo de la utopía de la igualdad, las desigualdades de origen no son merecidas. Nadie se las ha merecido y por eso hay que hacer algo.

La consideración de las desigualdades existentes como caprichos de la fortuna, es un momento fundamental de la teoría rawlsiana. José María González, que ha tenido la agudeza de señalar esta singularidad de Rawls, llega a la conclusión de que el autor norteamericano «parece confundir la situación presente de las sociedades occidentales con las leyes de la naturaleza», como si el ser rico o pobre fuera una «lotería genética» (González, 2006, 387). Eso le permite desentenderse del origen de las desigualdades ya que lo que haga la naturaleza «no es justo ni injusto». El moralista nada tiene que decir sobre cómo se han creado las desigualdades. El problema empieza a la hora de ver qué hacemos con ellas.

Con esta interpretación de las desigualdades Rawls toma una decisión que es clave para toda su construcción teórica. Si las desigualdades no son in- 
justicias porque nada tienen que ver con la libertad del ser humano, su tratamiento de la justicia tendrá más que ver con la generosidad de los que tienen que con los derechos de los que no tienen. Ese gesto teórico que rebaja la injusticia a desigualdad es lo que convierte su teoría de la justicia en una ideología liberal, es decir, en una teoría que aborda la justicia desde el prisma de la dominación (que atenta a la libertad) y no del empobrecimiento (que atenta a la igualdad).

Para cerrar el círculo de una teoría de la justicia como teoría de la desigualdad, Rawls tiene que hacer un importante ajuste teórico. Tiene que ajustar las cuentas con Rousseau, un autor al que tanto deben estos contractualistas. Es un punto fundamental que no puede pasar desapercibido ${ }^{8}$. Detengámonos, pues.

En Jean-Jacques Rousseau tenemos dos textos mayores, Discours sur l'origine de l'inégalité y el Contrat Social que forman parte de un todo. El primero no es un relato histórico (ni lo pretende: «busco el derecho y la razón. No me peleo por los hechos»), sino una ficción que tiene por objetivo aclarar precisamente la significación moral de las desigualdades de su tiempo. El segundo quiere ser la respuesta política de un sujeto moderno consciente de su responsabilidad histórica.

El Discours habla del estado natural y el Contrat del estado civil (de la sociedad moderna). Pues bien, lo que caracteriza al estado natural es la independencia, es decir, la ausencia de dominio o dominación porque todos los hombres son iguales ${ }^{9}$.

Lo que es importante señalar es que el hombre, en un momento dado, sale de ese estado natural y entra en sociedad, en el estado civil. Es un momento de madurez, de salida de la infancia, y coincide con el uso de la razón y de la voluntad. Pero es un momento traumático porque el uso de la razón se substancia en una transgresión del orden natural. Es la sociedad la que «deprava y pervierte al hombre», es decir, es la sociedad la que acaba con aquella «independencia» de la que disfrutaban aquellos seres iguales y libres.

Rousseau está estableciendo una relación entre la pérdida de la igualdad natural y la aparición de la sociedad civil con el único objetivo de señalar que las desigualdades de nuestro tiempo no son naturales, sino que son históricas, es decir, son producto de la acción humana. Las desigualdades sociales no

8 Sobre las consecuencias prácticas de este planteamiento, ver Pogge, Th., 2005, La pobreza en el mundo y los derechos humanos, Paidós, Barcelona, 198. También, F. Cortés, 2007, Justicia y exclusión, Siglo del Hombre Editores, Bogotá, 199. Con razón dice McIntyre que, para Rawls, «la justicia es asunto de modelos de distribución para los que el pasado es irrelevante», McIntyre, A., 1987, Tras la virtud, Crítica, Barcelona, 305-6.

9 Rousseau concluye su «Discours sur l'inégalité» diciendo: «de lo expuesto se deduce que siendo la desigualdad casi inexistente en el estado de naturaleza, recibe fuerza e impulso del desarrollo de nuestras facultades y de los progresos el Espíritu humano», en Rousseau, 1964, Oeuvres Complètes, III, Pléiade, 7. Ver el comentario de Derathé, R., 1995, J.J. Rousseau el la science politique de son temps, J. Vrin, Paris, 1995, 128. 
son moralmente neutras sino que son injusticias. Este es el punto crucial de su estrategia argumentativa.

Esta relación entre historia de la libertad e historia de la injusticia evoca el mito de la caída bíblica de los primeros hombres. Jacob Taubes dice que la historia del hombre comienza el «octavo día» de la Creación, que es el primer día del uso de la libertad y que coincide con una trasgresión que va a acabar con el orden natural del Paraíso (Taubes 1996, 349). Ese momento inaugura la historia del hombre y también supone el fin del estado natural (la expulsión del Paraíso).

Rousseau piensa que una política responsable tiene que hacerse cargo de ese hecho: del hecho que es el hombre quien ha destruido la igualdad originaria. La respuesta moral a esa consciencia consiste en plantearse rehacer la igualdad pero no con las armas del estado natural, el instinto, sino con las armas de la sociedad civil, a saber, la razón y la voluntad. Se trata de restablecer la igualdad pero desde la razón y la voluntad.

Esa es la tarea del Contrat Social que propone un acuerdo entre los hombres de su tiempo que garantice la igualdad pero desde una decisión libre. No vale cualquier consenso sino sólo el que parte de la libertad y llega a la igualdad. Se trata de «hallar una forma de asociación que defienda y proteja con todas sus fuerzas a la persona y a los bienes de cada asociado y por lo cual, cada uno de ellos, uniéndose a todos, no obedezca más que así mismo y continúe siendo libre como antes», es decir, que siga siendo el hombre independiente como lo era en el estado natural.

Lo que ocurre es que Rousseau se arruga y en vez de una política basada en la justicia, es decir, una política que sea respuesta a la injusticia, propone un nuevo orden en el que las decisiones se tomen libremente por todos, porque cada uno es igual al otro en libertad. Se canjea justicia por igualdad en la libertad.

Rawls no quiere caer en esa contradicción y por eso ataja el problema en su raíz: en vez de decir que las desigualdades son injusticias porque las ha causado el hombre, digamos que son producto del azar y de esa manera no hay que pensar la justicia como respuesta a la injusticia sino como reglas de juego en el que las decisiones se toman desde el supuesto que somos iguales en libertad.

Declarar a las desigualdades hijas del azar es una ingenuidad que no resiste el menor análisis. No hay más que ver cómo se han hecho las fortunas. Cuando Sancho trata de consolar a su señor, derrotado por el Caballero de la Blanca Luna, invocando a la caprichosa fortuna, le replica Don Quijote: «Lo que sé decir, es que no hay fortuna en el mundo... cada uno es artífice de su ventura». Las desigualdades en el mundo tienen padre y madre, son productos creados por el hombre, son artificios, aunque Don Quijote no explica si con buenas o malas artes. Unos heredan las fortunas y otros los infortunios. Se podrá hablar de fortuito a propósito de quien hereda no en cuanto a la na- 
turaleza de lo heredado. La cínica teoría de Anatole France - «el robo es un delito y el producto del robo, sagrado»- es insostenible.

Marx, que observa atentamente la jugada, denuncia lo que hay tras esa ingenuidad explicativa: despolitización de las desigualdades o «privatización de la injusticia». De lo que tiene que ocuparse la política es de reconocer y asegurar la igualdad en la libertad. Ahora bien, cómo cada cual lo use o qué provecho saque, eso ya es un asunto privado.

Al plantearse la justicia como reacción de un conciencia moderna (habitada por el principio de la igualdad) ante las desigualdades moralmente neutras ( $\sin$ que la pobreza ni la riqueza sean en sí mismas significativas), la justicia se reducirá a compensar la pobreza de los pobres, pero no a cuestionar la riqueza de los ricos. Lo que pone en movimiento a la justicia no está del lado del «objeto» (la desigualdad real) sino del «sujeto» (nuestra sensibilidad igualitarista que no tolera la existencia de la pobreza por ser inmerecida). Se invisibiliza la culpabilidad que causa la injusticia y se magnifica la responsabilidad ante la desigualdad presente.

7. La atemporalidad de Habermas y Rawls.

Quisiera terminar trayendo a colación dos reflexiones finales sobre Rawls y Habermas.

Dice Rawls que «las personas en la posición original no tienen ninguna referencia respecto a qué generación pertenecen». El experimento se ubica en una «posición originaria», es decir, se borra el tiempo de suerte que no hay manera de relacionar el presente con el pasado. Una consideración atemporal de la desigualdad.

Habermas dice algo parecido cuando «coloca la capacidad de reconocimiento del otro bajo la reserva de la contemporaneidad», es decir, la racionalidad comunicativa sólo funciona entre sujetos presentes capaces de argumentar. La fuerza argumentativa queda remitida al uso del lenguaje que hacen los hablantes que hablan. La racionalidad es presencialista. El «antes» sólo vale en tanto en cuanto es metabolizado por los presentes, es decir, contribuye a potenciar mi capacidad argumentadora, pero en sí mismo es mudo, irrelevante. Justo es reconocer que este planteamiento asusta al propio autor que se pregunta: «¿no será obsceno que los beneficiarios de normas que sólo se justifican por los efectos positivos que producirán después, soliciten de los aplastados y humillados un consentimiento contrafáctico?» (Habermas, 1991, 128). Lo obsceno es que sufrimientos pasados puedan ser justificados por el beneficio que nos reportan a nosotros, nacidos después. Parece duro pedir a las víctimas de los campos de exterminio que acepten su sacrificio porque es el precio de la paz y bienestar de las generaciones siguientes. Pero eso es lo que pide su modelo discursivo. En él el pasado se hace presente a través del uso argumental que hagan las generaciones presentes.

Esta atemporalidad o presencialismo es lo que impide entender la desigualdad como injusticia. El problema es el tiempo. La injusticia es una desi- 
gualdad que tiene en cuenta el tiempo porque es histórica, es decir, ha sido causada por el hombre. Por eso hay que ver lo que hay detrás del espejo, lo que se esconde tras la apariencia, lo olvidado por la presencia. Estamos hablando de la memoria. Queda abierta entonces la relación entre memoria y justicia, entre olvido e injusticia.

\section{Justicia y memoria}

1. Acabábamos la primera parte diciendo que lo que diferencia la desigualdad de la injusticia es el concepto de tiempo. El tiempo de la desigualdad es un concepto mítico del tiempo. Al ser la desigualdad producto del azar, es algo que está ahí, que es así, que se nos impone con la fuerza de un hecho casi natural o de un destino. Frente a ella el sujeto es inocente, como los héroes trágicos. El tiempo de la injusticia es histórico porque remite a una causa libre, a una acción humana. Hay un antes y un después de la injusticia: hay, antes, un ser libre y, después, una acción reprobable, por eso el sujeto de la acción no es inocente sino culpable.

Ahondando en uno y otro llega Rosenzweig a decir que en el tiempo mítico el hombre está solo, por eso no hay amor sino pasión. Al estar sometido a lo que acontece, nada ocurre en el tiempo mítico que cambie el rumbo del destino. Moisés y Edipo. Son vidas paralelas. Ambos nacen condenados a muerte. Recordemos, en efecto, que Moisés es un primogénito judío que debía morir por orden del faraón; antes de ser un salvado de las aguas fue un arrojado a las aguas. También Edipo debía morir por decreto del oráculo. Era el precio para que la casa real de Tebas se salvara de la catástrofe. A los dos, hombres ejemplares y líderes de sus pueblos, les sobreviene el mismo fin trágico: por querer hacer el bien acabarán desoídos y humillados. Al final se impone el principio: si nacieron condenados, acabarán condenados. Desde esta clave trágica se puede entender que Dios castigue a Moisés no por haber cometido una falta, sino por olvidar que él es una falta, un arrojado a las aguas, un condenado (Kovadloff, 1996, 92). A ese tiempo que se cumple inexorablemente sin que haya manera de cambiar su rumbo, llama Benjamin continuum.

Lo que caracteriza al tiempo histórico es la posibilidad de novedad, de que el futuro no sea destino o repetición, sino futuro, es decir, ruptura de ese destino y, por tanto, novedad. Ese tiempo que para los filósofos judíos alemanes modernos debe ser la alternativa no sólo a un tiempo arcaico sino al tiempo del concepto moderno de progreso que caracteriza a la modernidad, es el tiempo mesiánico y que se formula así: «el tiempo es el otro». Levinas construirá su potente concepto de alteridad a partir de esta concepción del tiempo (Sucasas, 2010, 262). 
El despertar del tiempo mítico, la interrupción de una lógica histórica que se construye sobre la injusticia, sólo es posible desde la aparición del otro, pero no al lado, sino de frente, enfrentándonos.

¿De qué otro estamos hablando? No es un otro cualquiera sino ese que nos pregunta, desde la experiencia de Auschwitz, «si esto es un hombre». El mismo al que se refería Antón Montesinos en su sermón de La Española cuando preguntaba a los encomenderos y conquistadores si estos, los indígenas, «¿no son acaso hombres?». O, si se prefiere, ese otro es el Autrui, al que se refiere Blanchot, cuando quiere dar a entender, con ese término, la chispa divina que sobrevive en seres humanos sometidos a las torturas más extremas y sin apariencia humana.

Jean Luc Nancy ha recogido esta capacidad interpelante o interruptora o anunciadora de novedad del ser humano bajo la figura de la ecceitas: es el «héme aquí» con el que se presenta una realidad que creíamos amortizada, pero que se nos revela cargada de verdad. Ecceitas es la figura de una presencia interpelante. Es una mostración que interpela desde una experiencia negativa que no se resigna a la insignificancia, sino que nos asalta como lo que da que pensar.

La ecceitas es el método filosófico de Benjamin: «no tengo nada que decir, sólo mostrar. No quiero ocultad nada valioso, ni apropiarme de fórmula espiritual alguna. Sólo los trapos, las sobras. Eso es lo que quiero inventariar y hacerles justicia» (GS V 574).

Al hablar de trapos no hay que pensar en l'Abbé Pierre, «El trapero de Emáus», sino en Karl Marx. El habló de trapos y habló mal porque trapos se dice en alemán Lumpen y Marx despreciaba al Lumpen, porque era un ejército de parásitos que no creaban riqueza. Marx sólo tenía ojos para el proletariado que, esos sí, hacían andar la rueda de la historia.

Benjamin hace salir de la oscuridad de la historia la figura inmensa del trapero. El trapero, en efecto, dispone de un punto de vista privilegiado para analizar las sociedades avanzadas. Al trapero no se le oculta que el sistema funciona creando desechos que luego recicla y aprovecha como alimento de la maquinaria. Las sobras son una realidad del sistema y también la metáfora de la exclusión. Lo que el sistema desecha no es sólo lo que circula por las cloacas o va al cubo de las basuras. Convierte en basura todo lo que usa, eso mismo que un momento antes ha sido festejado con todos los honores. El trapero es fuerte no sólo a la hora de diagnóstico de la situación sino de la salida de la crisis: hay que aguantar, como hace el trapero, a pie firme todo ese proceso de producción que acaba en las cloacas, es decir, hay que entender el sistema capitalista hasta el final. Y el final no es conservar o admirar nada sino consumir. Benjamin piensa que las teorías económicas fracasan porque no soportan el cara a cara con la miseria. Los políticos y sus economistas se retiran demasiado pronto a sus gabinetes para tratar de resolver un problema en vez de escuchar las razones que subyacen a los gritos de los desesperados. Hay 
que tomar la medida del desastre, contando los caídos, escuchando los relatos de los que huyen por hambre, anotando las víctimas que generan las decisiones de los poderosos, tomadas en algún lugar lejano. Ese es el secreto del trapero: mostrar los trapos, uno a uno, y escuchar su elocuencia. Así los salva, convirtiéndoles en principio del conocimiento y de la justicia.

La figura paciente del trapero cuya sabiduría consiste en dejarse impresionar, como haría una cámara fotográfica, de la elocuencia de los trapos, nos lleva directamente a esa forma de conocer que Benjamin llama verdad y que contrapone a la del mero conocimiento.

2. En el Prólogo al Origen del Drama Barroco Alemán, Benjamin distingue entre verdad y conocimiento. Propio del conocimiento es el juicio o la intencionalidad, es decir, la luz que proyecta el sujeto sobre el objeto. Las cosas son vistas con la misma luz que proyecta el sujeto. Se conoce conforme al modo de ser del sujeto cognoscente. La verdad, por su parte, es revelación, la presencia de lo ocultado. No es lo que nosotros hacemos presente sino lo que se nos hace presente. Esa presencia tiene una doble exigencia: nos invita a la acogida de algo que se nos da, de ahí el conocimiento como agradecimiento (Danken) y se nos presenta como lo que da que pensar (Denken).

2.1. Ése es el lugar de la memoria. Los alemanes lo tienen más claro porque Gedächnis es Danken y Denken. Pero más allá de la filología alemana, podemos entender perfectamente que hay acontecimientos o hay aspectos de cualquier acontecimiento que escapan al conocimiento, que no son pensados porque son impensables. Pensemos en el acontecimiento Auschwitz que fue impensado e impensable; pero pensemos también en esos aspectos invisibilizados en los procesos históricos porque se frustran y pasan a la categoría de accidentes. De los accidentes, decía Aristóteles, no hay ciencia. Eso no interesa al conocimiento, eso no es combustible del conocimiento.

La memoria se sitúa exactamente en ese punto de la historia en el que algo impensable para los cánones convencionales del conocimiento ocurre y en vez de dejarlo ir por el sumidero de la historia, es rescatado por una categoría que lo eleva a la condición de lo que merece ser pensado, de lo que da que pensar. Esa es la memoria.

Pero estamos yendo muy deprisa porque acabo de insinuar una idea de la memoria que es nueva. Conviene echar la mirada hacia atrás para saber de dónde venimos. Eso debería ayudar a desentrañar el tosco debate entre historia y memoria en el que algunos han quedado prendidos o prendados de visiones arcaicas de la memoria.

a) Digamos, de entrada, que el pasado es un rico yacimiento de sentido al que acude, por supuesto, la historia, pero también el arte y también la filosofía que tiene al tiempo como uno de sus desafíos más constantes. Ninguna disciplina ni siquiera la historia puede pretender tener el monopolio del pasado, ni por tanto, sobre la significación de la memoria, que se dice de muchas maneras. 
Un ejemplo de lo original de una visión literaria del pasado es Cien años de soledad, de García Márquez. La historia de Macondo es la del Nuevo Mundo. Pues bien, sus habitantes nacen todos enfermos o, mejor, apestados. Son víctimas de la peste del olvido, olvido que será la causa de un sinfín de desdichas y violencias. Macondo, para poder presentarse ante la historia, tiene que vestirse de Nuevo Mundo. Sólo así podrá ser reconocida por los grandes hombres, sujetos de la historia, que acaban de llegar. Claro que Macondo tiene una existencia anterior y que hay un mundo viejo antes de que aparezca el nuevo. Pero eso es la prehistoria a la que hay que renunciar si esos pueblos quieren entrar en la historia. Esa renuncia a sus raíces es el olvido impuesto por quien les da el nombre de Nuevo Mundo. Se entenderá por qué García Márquez se despacha a gusto en Los funerales de la Mamá Grande cuando dice: «Es hora de contar los pormenores de esta conmoción nacional antes de que lleguen los historiadores».

La memoria cotiza al alza. En España afloran en estos tiempos los recuerdos de la guerra civil con una intensidad desconocida, al tiempo que se multiplican las críticas a la transición política por su amnesia. Es, desde luego, un fenómeno mundial. El sexagésimo aniversario de la liberación de Auschwitz movilizó muchos más recuerdos que los del quincuagésimo. Se habla de memoria de la esclavitud, de la colonia, de la conquista... No siempre ha sido así. $\mathrm{Al}$ contrario, venimos de una larga noche de olvido, la que cubrió occidente después de la II Guerra Mundial. El secreto de este despertar está en la elaboración filosófica de la memoria.

b) Una rápida mirada sobre la evolución de la categoría «memoria» nos revela que para los antiguos y medievales la memoria era, en primer lugar, un sensus internus, una facultad menor que sólo produce sentimientos. En segundo lugar, una categoría conservadora, cultivada por los tradicionalistas. La pretensión de la memoria era la de convertirse en norma y hacer que el presente fuera reproducción del pasado, de lo que siempre había sido ${ }^{10}$. La modernidad entendió bien esta pretensión normativa del pasado, por eso, ella, que venía con la idea de construir un tiempo nuevo, distinto de lo que siempre había sido, tuvo que declarar la guerra a la memoria. Habermas lo expresa a su modo diciendo que la modernidad es post-tradicional y Foucault apunta en la misma dirección cuando afirma que lo decisivo para los nuevos tiempos es «el presente». Para la nueva autonomía del sujeto, en asuntos de moral y política, la pretensión normativa del pasado era sencillamente inaceptable; y para la nueva ciencia, dispuesta a progresar en el conocimiento «mediante reducción de las cosas a sus causas», como decía Descartes, «no hay ninguna nece-

10 Este aspecto está bien recogido en la novela de U. Eco, El nombre de la rosa. Jorge, el auténtico guardián de la biblioteca, no soporta que nadie busque en los libros novedades. El ideal del monje es alguien que transcribe documentos siendo analfabeto. 
sidad de la memoria» ${ }^{11}$. Este entendimiento entre amnesia y modernidad explica que los movimientos antimodernistas y antirrevolucionarios recurran a la memoria como antídoto eficaz sea contra la autonomía del sujeto (proclamando la prioridad de la sociedad sobre el individuo), sea contra el progreso (predicando el valor normativo de la tradición).

En tercer lugar, es una categoría a posteriori y no a priori. En Platón, las ideas tienen su mundo propio, un mundo Ideal que no es este mundo. Cuando dice en el Menon que el conocimiento es anámnesis (98a), está dando a entender que el conocimiento humano sólo puede ser reconocimiento de unas verdades que existen previamente a la memoria. Gracias al recuerdo «atamos» o reenviamos la experiencia mortal al Eidos. El mundo del Eidos posee una prioridad lógica sobre el conocimiento humano que tiene que remitirse a aquél por el camino del recuerdo.

c) Esto cambia en el siglo XX. El primer asalto al carácter conservador de la memoria tiene lugar en torno a la I Guerra Mundial y lo protagonizan los sociólogos de la memoria, con Maurice Halbwachs, el autor de Les cadres sociaux de la mémoire, 1925, y Mémoire colective, 1950 (escrito póstumo. Semprún cuenta cómo muere en sus brazos, en Buchenwald, mientras le recita un poema de Beaudelaire: O muerte, vieja capitana, hora es de levar anclas, etc., mientras el agonizante sonríe «con la mirada, sobre mí, fraterna») ${ }^{12}$. Responden al vértigo que supuso esa guerra - vértigo debido al fracaso del proyecto ilustrado y a la irrupción de la técnica - con la tesis de que la memoria es un momento fundamental de la construcción de la realidad, de ahí la complicidad entre construcción de la historia y pasado. Una complicidad pues entre progreso y pasado. Es lo que hizo Halbwachs que hizo de la memoria un arma de combate, primero para impulsar los ideales socialistas, cuando en los años veinte se pensaba que el movimiento obrero nadaba a favor de la corriente; y luego, como arma antifascista, cuando en los años treinta no parecía haber más realidad en París que la cruz gamada. Con el arma de la memoria se podía decorar la capital francesa con la simbología revolucionaria de 1789 , de 1830 , de 1848 y de 1870.

El segundo cambio cuestiona el supuesto de que la memoria es sentimiento $\mathrm{y}$, por tanto, no puede producir conocimiento. El cambio se produce, efectivamente, en torno a la II Guerra Mundial. Su exponente más señalado es Walter Benjamin. Con él la memoria pasa a ser una «teoría del conocimiento». El lugar de esa teoría son sus Tesis sobre el concepto de historia que no las presenta como suplemento de la historia (como hacen los historiadores que se ocupan de los «testimonios» como materiales del conocimiento histórico), sino como conocimiento del pasado, un conocimiento rival de la historia, o más precisamen-

11 El texto de Descartes está tomado de Cogitationes privatae y es citado por J. Le Goff, 1988, Histoire et mémoire, Gallimard, Paris, 154.

12 Semprún, J., 1995, La Escritura o la Vida, Tusquets, Barcelona, 36. 
te de las concepciones de la historia con las que él polemiza. Notemos que estas Tesis son un tratado de la memoria. Si Benjamin no las titula Tesis sobre el concepto de memoria es porque entiende que está proponiendo una nueva teoría de la historia y no sólo algo reducido al ámbito de la «memoria».

Benjamin sabe que se adentra por un sendero desconocido y peligroso. Es tan consciente de su novedad que se construye un lenguaje a la altura de esa novedad. Si en alemán se utilizan los términos Erinnerung o Gedächtnis para designar la memoria, él prefiere desempolvar un viejo término, Eingedenken (que podríamos traducir por remembranza, recordación o rememoración), para dar a entender que se trataba de algo distinto.

Benjamin presenta su tesis polemizando con las dos grandes teorías de la historia del momento: el historicismo que fija como cometido de la historia «conocer las cosas tal y como realmente han sido», es decir, entra en polémica con o contra una lectura del pasado que dice ser conocimiento pero conocimiento «científico» del pasado; y con la las filosofías modernas de la historia que manejan una concepción del tiempo inagotable, imparable y salvífico.

Pues bien contra esa doble pretensión de la historia se levanta la memoria: contra la idea de que hay un conocimiento «científico» del pasado; que se puede conocer el pasado tal y como fue. Este conocimiento científico sólo tiene ojos para los hechos, lo que ha sido; pero lo que no es, lo que quedó derrotado y abandonado, no forma parte de la realidad o tiene un significado «subalterno», subordinado a lo que consiguió ser. Para la memoria la realidad son los hechos y los no-hechos. También contra la pretensión salvífica de las filosofías modernas de la historia. Como si hubiera una lógica de la historia que, de seguirla, nos llevaría a la felicidad. La idea de que siempre hay tiempo, de que el tiempo es inagotable, de que vamos hacia mejor, todo eso es expresión de una conciencia mítica, más que racional, del tiempo.

Frente a estas dos teorías de la historia, la memoria se presenta como capaz de conocer los no hechos y también de ver la fuente del futuro en el pasado derrotado.

Pero hay todavía un tercer elemento que imponen los acontecimientos: el «deber de memoria». Lo que hemos descubierto hasta ahora es una posible complicidad entre memoria y futuro, por un lado, y memoria y conocimiento, por otro. Con la memoria se puede construir el futuro y además conocer mejor la realidad. Hay, empero, algo más: el deber de memoria, la memoria como deber.

El descubrimiento de este aspecto de la memoria ha sido reciente. Tiene lugar después de Auschwitz cuando los supervivientes lanzan desde todos los campos el «nunca más» y apelan a la memoria como recurso necesario. Los supervivientes han hecho una experiencia tan extrema de inhumanidad que se apresuran, tras su liberación, a avisarnos de que la humanidad no puede permitirse una repetición de ese horror porque sucumbiría en el intento. Y el antídoto contra esa tentación es la memoria. Llama la atención que la estrategia 
contra el peligro de deshumanización sea algo tan modesto como la memoria. Podían haber invocado otras causas más enérgicas y aparentemente más eficaces: más progreso... o más educación... o un plan Marshall... En lugar de ello, el recurso a la memoria. Nace así lo que Adorno llamaría el Nuevo Imperativo Categórico: «Hitler ha impuesto a los seres humanos en su estado de ausencia de libertad un nuevo imperativo categórico: orientar su pensamiento y su acción de modo que Auschwitz no se repita, que no vuela a ocurrir nada semejante» (Adorno, 1966, 356).

¿Cómo entender eso del «deber de memoria»? Aristóteles dice que lo que distingue la memoria animal de la humana es que ésta puede ser activada a voluntad, poder evocar sentimentalmente el pasado y hacer aflorar la añoranza o la nostalgia. Aquí se trata de otra cosa, de un deber de recordar pero para conocer. El deber de memoria se inscribe en nuestro modo de pensar una vez que hemos tomado conciencia de los límites del conocimiento y de su correspondiente pretensión de invisibilizar el sufrimiento. La memoria, al retrotraernos a lo que da que pensar, se aproxima a la figura del «acontecimiento» en la filosofía de Alain Badiou. Hay acontecimientos, dice este autor, tan cargados de significación que no encajan en esquemas interpretativos previos sino que se convierten en lo que da que pensar. Este exceso se produce en acontecimientos políticos o incluso en expresiones poéticas, como ocurre con Paul Celan. Querer interpretar ese exceso poético a partir de una filosofía previa, como la de Heidegger, era condenar la poesía de Celan a la insignificancia ya que esa poesía demandaba efectivamente una prolongación filosófica, pero no a una previa, como la heideggeriana, sino a una nueva que tomara la poesía de Celan como lo que da que pensar.

La memoria se hace cargo de eso impensable por el conocimiento pero que, al haber tenido lugar, da que pensar. Estamos en el epicentro del concepto de memoria.

2.2. El deber de memoria se inscribe pues es nuestro modo de pensar y eso vale a la hora de interpretar lo que ocurrió en Auschwitz y lo que ocurre con lo oculto en muchos otros acontecimientos. No podemos pensar, a partir de ahora, sin tener en cuenta la memoria, el «deber de memoria», o, mejor, para quitarle toda connotación moralizante, la aparición de un Nuevo Imperativo Categórico, que consiste en repensar la verdad, la política y la moral teniendo en cuenta la barbarie. No es sólo un imperativo moral, sino también metafísico. De ahí nace un exigente programa filosófico que afecta a la metafísica, a la política, a la ética y a la estética.

En primer lugar se trata de re-pensar la verdad. Y eso significa no reducir realidad a facticidad, es decir, reconocer que forman parte de la realidad los no-hechos, sin-nombre, los no-sujetos. Durante siglos la filosofía había seguido al pie de la letra el mandato de Aristóteles que declaraba los no-hechos irrelevantes para el conocimiento: «de los no hechos y de los accidentes, de- 
cía en su Metafísica, no hay ciencia». Auschwitz despide a Aristóteles al hacer visible lo invisibilizado por el saber canónico.

La memoria hace visible lo invisible. Si analizamos el crimen en el Lager detectamos una clara estrategia de invisibilización. En el Lager, en efecto, no se trataba sólo de matar judíos, sino de expulsarlos de la condición humana. Para eso era muy importante que la víctima interiorizara que no formaba parte de la especie y que se borrara toda diferencia entre víctimas y verdugos, tal y como ocurrió con ese partido de fútbol entre oficiales nazis y miembros del Sonderkommando, a las puertas mismas del crematorio.

Esta era, a juicio de Levi, la mayor inmoralidad pensable. Esta extraña confraternización suponía para los verdugos nivelación moral respecto a las víctimas. Iguales en el mal y en el bien. Levi lo expresa con claridad meridiana cuando, tras referirse al partido del fútbol, pone en boca de los verdugos estas palabras: «os hemos, abrazado, corrompido, arrastrado a polvo como nosotros. También vosotros, como nosotros y como Caín, habéis matado a vuestro hermano. Venid, podemos jugar juntos» (Levi 1989, 46).

Frente a todas estas estrategias de invisibilización de las víctimas, está su mirada, que será invisible para los verdugos o para los demás pero no para ellas mismas.

La traducción epistémica de esta mirada ampliada de la realidad —ampliada porque la realidad no se agota en la facticidad - se concreta en el reconocimiento de la insuficiencia del conocimiento. Lo impensable es lo da que pensar. Ese envite altera el valor de los conocimientos conquistados por el sujeto. Pasamos del conocimiento a la verdad, en la jerga benjaminiana.

Para entender la novedad epistémica de la categoría memoria puede ser ilustrativo remitirnos a la escultura de Eduardo Chillida. Sus monumentales obras están construidas en hierro u hormigón. Característico suyo son esos huecos o vacíos gracias a los cuales otros mundos, distintos de la materia de la obra, vienen a inscribirse en el espacio escultural para alterarle sustantivamente. La presencia de lo ausente cuartea la contundencia de la materia; lo que sólo es viento vence al hierro, retorciendo su masa hasta vencerla. La memoria son esos huecos que permiten a la ausencia hacer presente.

En segundo lugar, re-pensar la política teniendo en cuenta la barbarie experimentada, significa cuestionar el progreso como lógica de la política moderna. Del progreso decía Ernst Jünger que era «la iglesia más popular del siglo XIX, la única que puede vanagloriarse de disfrutar de un poder real y de un credo libre de toda crítica» (Jünger, 1990, 101-2). Todo el mundo se sentía progresista, los de un bando y los del contrario, porque serlo era lo mismo que estar vivo y que ser un ciudadano a la altura de su tiempo. Es que el progreso era «el resorte moral de nuestra época» (Jünger, 1990,102). Pero no se trataba sólo de prestigio social. También se asociaba moral a progreso de la misma manera que barbarie a primario. Lo primario es lo que se acerca a la animalidad mientras que progreso, lo que se aleja de ella. Se confunde pro- 
greso con el proceso civilizatorio que ha ido conformando a la especie humana a lo largo de los siglos. Por eso Victor Cousin da un paso más e identifica éxito con moralidad. El éxito del ser humano consiste en haberse constituido como tal, lo que sólo era posible derrotando la animalidad. Ese éxito es la mejor expresión de la moralidad, «si no fuera así — si el vencedor no fuera más moral que el vencido - habría contradicción entre la moralidad y la civilización, lo que es imposible, ya que una y otra no son sino dos lados, dos elementos distintos pero concertados de la misma idea» (Cousin, 1992, 242). Victor Cousin, al confundir progreso y moralidad, está expresando una profunda convicción moderna que no se libra, por cierto, de la mordaz ironía de Cervantes cuando, en El Quijote, presenta a su escudero, ese labrador que «nació de padres pobres pero honrados», como «un hombre de bien (si es que ese título se puede dar al que es pobre» (Parte I, VII).

La crítica de Benjamin al progreso es doble. Por un lado, declara que el tiempo del progreso es mítico. Propio del mito es la repetición, el estado de dormición (Schlaf, sommeil- no Traum o rêve) o la angustia porque la existencia se ve prendida de una sucesión que no tiene fin. El tiempo del progreso es mítico aunque se presente como inagotable (siempre hay tiempo), imparable (su lógica se impone en la historia necesariamente) y salvífico (el tiempo traerá la solución). Es mítico ese tiempo porque el pretendido avance es repetición, eterno retorno. Nada explica mejor el carácter mítico del progreso que la moda: es lo más actual pero siempre repite el pasado. Es lo de siempre en lo nuevo: «das Immergleichen am Neuen».

Siempre se ha admitido que el progreso conlleva la posibilidad del fracaso: con el invento del navío, aparece el naufragio; con el invento del avión, aparece la catástrofe aérea, estrellarse contra el suelo; con la electricidad, la electrocución; con la relatividad, la bomba atómica...

Pero considerábamos esas catástrofes «accidentes de la velocidad». El problema ahora es que la velocidad ha adquirido tal aceleración que es el propio tiempo del progreso lo que es catastrófico. Tengamos en cuenta que la velocidad de referencia en nuestro tiempo es la de la luz y eso supera los límites del ser humano. La velocidad de la luz son $300.000 \mathrm{~km} / \mathrm{seg}$. A esa velocidad sólo aguantan las máquinas. Los fotones, esos sí, no envejecen. Más allá de esa barrera no hay antes y después, no hay tiempo. El progreso es ya catastrófico.

La segunda crítica al progreso es más radical pues le compara con el fascismo. Se puede calibrar la provocación de Benjamin cuando en ese contexto proclama, en su Tesis Octava, que fascismo y progreso convergen. Tesis arriesgada pues no solemos representar al fascismo como una recaída en la barbarie de la que la humanidad salió hace muchos siglos. ¿Qué es lo que tienen en común? La moralidad del éxito, esto es, aceptar con toda normalidad la producción de víctimas, como si la conquista de nuevas metas justificara de por sí pagarla con vidas y haciendas de los débiles. Lo común es la naturalidad con la que se entroniza la consecución de los objetivos, subordinando a 
tal fin cualquier medio que se juzgue apropiado. El fin sí que justifica los medios aunque sea suponga pisotear algunas florecillas al borde del camino. Benjamin da la vuelta a la idea de Jünger y Cousin que quisieron hermanar progreso con moralidad, convirtiendo así al progreso en cómplice de la barbarie. Progreso y barbarie no se oponen pues por principio. El progreso puede ser catastrófico.

Repensar la política desde una consideración crítica del progreso significa someterle al juicio moral. Que hay progreso técnico y científico, es indiscutible; que ese progreso indiscutible comporte también un progreso moral, es discutible, es decir, que se puede y se debe debatir. Lo hizo Kant cuando, a propósito de la Revolución Francesa, se preguntó si ese hito histórico supuso o no un avance moral. El problema, para responder bien, estribaba en cómo medirlo, con qué criterios evaluar ese posible progreso moral. Se arriesgó a dar uno, a saber, el entusiasmo de los espectadores. Pero el planteamiento de Kant no nos sirve. Los espectadores, en efecto, no son neutrales y si lo son, es a costa de la moral. Georg Steiner (Steiner, 1973, 46) dice que nueve de cada diez europeos miraron a otro lado durante el antisemitismo nazi. No vale pues el entusiasmo del espectador para inyectar moralidad al progreso y por tanto para superar críticamente una lógica política basada en el progreso. El criterio tiene que ser otro, tal y como propone Adorno cuando dice que no es lo mismo someter el progreso a la humanidad que tratar a la humanidad como medio del progreso.

Se está repitiendo lo que cuenta Platón en el diálogo Protágoras: los dioses, a la vista de lo mal que lo tenía el hombre en su lucha con los animales, deciden enviarle el fuego y las artes del fuego para que aprendiera a defenderse. Se quedaron atónicos al ver que usaban el arte de las armas fabricadas con fuego para... matarse entre ellos. "Atrás a toda marcha» ${ }^{13}$ es el título de un escrito de Humberto Eco sobre la deriva del progreso. El afán de innovar la tecnología en ordenadores, por ejemplo, está llegando al absurdo de crear programas perfectamente inservibles pero que se compran e instalan porque son el último grito de la técnica. Progreso también puede significar dar un par de pasos atrás. Su artículo acababa así: «itendamos al futuro! ¡Atrás a toda máquina!». La respuesta a un concepto de tiempo entendido como constante aceleración es la interrupción. La revolución significa ahora tirar del freno de emergencia.

En tercer lugar, re-pensar la ética. Ernst Tugendhat, que se ha dedicado toda su vida a probar la calidad de las fundamentaciones de la ética, ha llegado a la conclusión de que todas se basan en un prejuicio humanitario: en la igual dignidad de los seres humanos. Hay que buscar en el convencimiento generalizado de que todos los seres humanos son iguales en dignidad la explicación de por qué somos o debemos ser buenos. Ahora bien, lo que llama la

13 En El Periódico de Catalunya, 20 de octubre del 2008. 
atención en los testimonios de los supervivientes es que, para sobrevivir, había que colgar la dignidad a la entrada del campo. Abundan los testimonios en el sentido de que para sobrevivir había que echar mano de todos los argumentos, sin pararse a mirar su clasificación moral.

Elie Wiesel precisa esta idea al decir que, en el Lager, lugar del ultraje y de la degradación moral, la dignidad era posible sólo hasta un determinado momento de sufrimiento a partir del cual era impensable. «Los santos son los que mueren antes del final» (Wiesel 1961, 57), dice. Se puede ser digno hasta cierto nivel de tortura, pero una vez superado ese umbral no hay dignidad, ni santidad, ni moralidad posible. Claro que hubo excepciones, pero eran eso, casos excepcionales. Eso explica en parte el sentimiento de culpa de los sobrevivientes. Recuerdan que los mejores quedaron en el camino y que, para seguir adelante, tuvieron que bajar la cabeza, como les ocurrió cuando no fueron capaces de quitarse la gorra en señas de respeto por quien iba a morir ahorcado gritando para animarles «icompañeros, yo seré el último!». En lugar de ello recuerda un pesaroso Levi «no nos hemos descubierto la cabeza más que cuando el alemán nos lo ha ordenado... ya no quedan hombres fuertes entre nosotros. El último pende ahora sobre nuestras cabezas y para los demás pocos cabestros han bastado. Pueden venir los rusos: no nos encontrarán más que a los domados, a nosotros los acabados, dignos ahora de la muerte inerme que nos espera. Destruir al hombre es difícil, casi tanto como crearlo: no ha sido fácil, no ha sido breve, pero lo habéis conseguido alemanes. Hénos aquí dóciles bajo vuestras miradas: de nuestra parte nada tenéis que temer: ni actos de rebeldía, ni palabras de desafío, ni siquiera una mirada que juzgue» (Levi, 1987, 157). Y en el estremecedor relato de Gradowski, el Sonderkommando que escondió su relato entre las piedras de la cámaras de gas antes de ser asesinado, se reconoce con desconsuelo: «la moral, la ética, igual que la vida, yacen en una tumba» (Gradowski, 2001, 84).

No tuvieron dignidad, pero ¿fueron inmorales? Para hacernos una idea de lo que significa un comportamiento moral en el campo, Levi recurre a la paradógica expresión de «suerte ética». Remitir al azar algo tan de la libertad como la moralidad, parece extraño. Pero así era. En el campo había que tener suerte para vivir, como dice Semprún.

Pero Levi va más lejos. Para sobrevivir moralmente también hacía falta suerte. Dice Levi: «El sobrevivir sin haber renunciado a nada del mundo moral propio no ha sido concedido, si exceptuamos aquellos casos en los que la fortuna ha intervenido de una manera directa y poderosa, más que a poquísimos individuos superiores, de la madera de los mártires y de los santos» (Levi, 1987, 98-99). Notemos esta extraña referencia a la «fortuna» porque está planteando algo tan paradójico como «la suerte moral».

¿Qué significa exactamente eso de la «suerte moral»? El reconocimiento de su rareza y esto dentro y fuera del campo. No podemos relacionar la moralidad con una propiedad que siempre está ahí, como connatural a la condición 
humana, y que sólo espera ser activada. Éste es el esquema de las teorías modernas de la moral, cuando dicen basar la moralidad en la dignidad con la que todo ser humano viene al mundo. Tenemos que entender la moralidad, la dignidad o incluso la humanidad, más bien como punto de llegada que de partida. Una conquista.

No somos quien para preguntarnos por la dignidad de los deportados cuya inmensa mayoría superó el umbral de humanidad posible al que se refería Wiesel. Pero sí por la nuestra, los nacidos después de Auschwitz. Esa ética sólo puede consistir en responder a la pregunta que nos hace Levi con el título de su obra: «si esto es un hombre» ¡Ecce homo! La ética consistiría entonces en responder de la inhumanidad que se nos pone delante. La actitud ética a la altura del campo consiste en hacerse cargo de la inhumanidad del otro. En el campo nace la ética de la alteridad o de la compasión y se clausura la ética de la buena conciencia.

3. La memoria es justicia. Con lo dicho he querido dejar constancia del músculo teórico de la memoria. Este término es para la filosofía una categoría rigurosa que poco tiene que ver con el uso coloquial del término o con lo que por ello entienden los historiadores. No es un mero sentimiento (evocación sentimental del pasado), ni un mero conocimiento (la información que proporciona un testigo), sino un imperativo categórico que aúna experiencia y conocimiento.

Esta es la categoría, dotada con los contenidos que han ido apareciendo, que hay que tener presente a la hora de afirmar que la memoria es justicia.

Es una afirmación extraña, una rareza, que va contra contracorriente. Va, en efecto, contra la atemporalidad de la teoría rawlsiana de la justicia y contra la eternización del presente que caracteriza la simultaneidad habermasiana. Nunca ha sido la justicia memoria.

Prueba de la dificultad de pensar una justicia que tenga en cuenta el tiempo es el hecho de que incluso aquellas aproximaciones teóricas que pudieran entenderlo, se blindan conscientemente contra ella. Pienso en las teorías de la justicia global tan sensibles a la universalización espacial de la justicia y tan desconfiadas de la universalización temporal. Y «como del lobo un pelo», baste esta muestra. Osvaldo Guariglia, en un fino estudio sobre la justicia global de obediencia rawlsiana, se ve obligado a precisar que «la desigualdad entre el desarrollo de los distintos países no es por sí misma un hecho injusto». Es una precisión que le debe a Rawls, pero le parece tan excesiva que se ve obligado a sacar de ese cesto de desigualdades históricas que no son injusticias a países «con un pasado reciente de explotación colonial, como la mayoría de países sub-saharianos de África» (Guariglia, 2010, 114). Las desigualdades recientes sí son injusticias, pero ¿por qué no las antiguas si no han sido reparadas? Parecería que es la lejanía en el tiempo la que disuelve las injusticias en desigualdades. 
Otro caso llamativo es el del ya mencionado Amartya Sen. Ya hemos visto con qué brío critica la teoría rawlsiana en nombre de un planteamiento guiado por la idea de que la justicia es respuesta a la injusticia. Ahora bien, por si alguien cae en la tentación de pensar que las injusticias tienen voz propia y que pueden hacer preguntas por las causas de su mal o exigir a otros responsabilidades, recurre al criticado pero amigo Rawls para precisar que «las influencias procedentes del pasado no deberían afectar un acuerdo basado en principios encargados de regular las instituciones» (Sen, 2010,162), es decir, las injusticias pasadas no deben influir en la conformación de los criterios de justicia. Lo que le no le convence a Sen es que ese experimento, necesario para destilar el concepto de imparcialidad, se empeñe en forzar una «solución única» encaminada a definir la pureza de lo justo, en vez de dejar fluir razones válidas para luchas contra la injusticia. En eso se diferencian, no en el (nulo) papel que juegue el pasado.

Extraña relación, de entrada, esta de la justicia con la memoria. Y una vez dentro habrá que responder a la pregunta ¿qué significa eso de que la memoria es justicia? Responderé a la pregunta con seis tesis y un gesto.

3.1. Sin memoria no hay injusticia.

Esto lo entendió bien Horhkeimer cuando escribe que «el crimen que cometo y el sufrimiento que causo a otro sólo sobreviven, una vez que han sido perpetrados, dentro de la conciencia humana que los recuerda, y se extinguen con el olvido. Entonces ya no tiene sentido decir que son aún verdad. Ya no son, ya no son verdaderos: ambas cosas son lo mismo» (Horkheimer, 1976, 16).

Sin memoria las generaciones siguientes no tendrán, claro, ni idea de lo que ocurrió; más aún, sin memoria es como si la injusticia no hubiera ocurrido nunca y el mundo pudiera organizarse como si la barbarie no hubiera tenido lugar. Si el proyecto nazi sobre los judíos hubiera triunfado, hoy los jóvenes de Oswiecim jugarían tan felices a fútbol sobre los campos de Auschwitz, como si nada hubiera ocurrido.

Se entenderá por qué el vencedor, es decir, el que comete la injusticia, no da por terminada la faena con la perpetración del acto. Sabe que tiene que afanarse también en el olvido del mismo. Y es que en el mismo crimen o en la misma injusticia, hay dos muertes en juego: la física y la hermenéutica. Hay que borrar las huellas del crimen no con un burdo negacionismo, sino privando de significado al crimen. La cultura occidental ha sido maestra en la invisibilización del crimen. Se ha empeñado en ello la teología («matar los cuerpos para salvar las almas», que decía Torquemada), la filosofía («el progreso conlleva pisotear algunas florecillas al borde del camino», que escribía Hegel) o el arte (esos cuadros de Berruguete que pintan a torturados por la Inquisición con rostros felices). Por olvido hay que entender invisibilización de la víctima o privación de significado. 
La batalla de la memoria la tenían perdida las víctimas desde el momento en que asociábamos memoria a memoria voluntaria. La memoria quedaba así a merced del vencedor que era el único que tenía conocimiento documentado de lo que ocurrió. Así hasta que Benjamin detecta un extraño elemento subversivo - «el ahora»- es decir, ese momento no amortizado del pasado vencido que clama justicia, ese momento de vida oculto en las ruinas que parecen muertas o naturalizadas. Ese «ahora» del pasado puede asaltarnos sin pedir permiso y puede así derrotar las estrategias de olvido. Si es verdad que el vencido no está a salvo mientras el vencedor ande suelto porque puede añadir a la muerte física la hermenéutica, tampoco el vencedor puede descansar tranquilo mientras haya una huellas, así sea mínima, de lo que en realidad ocurrió.

Sin memoria no hay, pues, injusticia, pero tampoco justicia. Eso plantea un colosal problema porque lo que se está queriendo decir es que sin memoria de todas las injusticias no hay teoría posible de la justicia ya que la idea de teoría conlleva la de universalidad. Digo que estamos ante un colosal problema porque son muchas las injusticias definitivamente olvidadas. Tener presente todas las injusticias supera la capacidad humana. Sería, más bien, como dice Horkheimer la prerrogativa de una mente divina. ¿Cómo entonces pensar la justicia si hay que hacerlo con una mente humana? «Tal es la pregunta de la filosofía», una pregunta aporética pues el ser humano no puede renunciar a la justicia pero le falta la potencia de una memoria divina para poder convocar todas las injusticias.

3.2. La justicia como memoria determinada de la injusticia. Tenemos que pensar entonces la justicia teniendo en cuenta la incapacidad radical de hacer memoria total de la injusticia.

Aclaremos de entrada que la memoria no afecta por igual a todos los pasados. Hay un pasado presente, que no merece ser recordado porque ya está presente. Es el pasado de los vencedores. Carece de poder innovador porque su sentido ya ha sido amortizado y absorbido por el presente. Sólo es creador el pasado de los vencidos o el de las víctimas. Pero ¿cómo hacer justicia a ese pasado injusto que podemos conocer o que puede asaltarnos? Hay que fijarse en los daños recibidos. Veremos que los hay reparables e irreparables.

Respecto a los reparables, sólo cabe la reparación por parte de la sociedad que recuerda. Es lo que de una manera u otra intentan hacer las leyes de la memoria histórica que se plantean reparar material o formalmente a colectivos victimizados. A los gobiernos contemporáneos les cuesta menos reparar económica que moralmente. La Sala de lo Militar del Tribunal Supremo ha denegado (16 de febrero del 2011) la revisión de la sentencia del consejo de guerra que condenó a muerte al poeta Miguel Hernández. Se escuda en la Ley de la Memoria Histórica para decir que ya ahí se reconoce de una manera general «la injusticia radical» de esas sentencias, pero se niega a «declarar nula 
la pena», una competencia suya. El alto Tribunal se escuda en el juicio político de Las Cortes para escatimar la reparación moral.

Pero ¿qué justicia cabe con lo irreparable? «Pasar página», «echar al olvido»... eran las soluciones habituales. Es posible, sin embargo, otra respuesta: hacer memoria de lo irreparable. Reconocer la deuda con el pasado y hacer duelo por los sufrimientos sobre los que está construido nuestro bienestar.

Es desde luego una forma muy modesta de justicia pero es fundamental. Si renunciáramos a ella, estaríamos diciendo que la justicia se mide por el verdugo, por su capacidad de reparación o por el castigo que se le puede infligir, y no por los daños causados a las víctimas. Pero la justicia está en función del otro (del que sufre el daño) y no de nosotros (sea la capacidad del quien hace el daño o de nosotros que decidimos si es injusto). Por eso es importante la memoria de la injusticia, porque aunque no conlleve reparación material del daño, reconoce la vigencia del derecho de las víctimas, aunque pase mucho tiempo y no haya ser humano capaz de una reparación adecuada. Hay que revisar figuras tan asentadas en el derecho como la amnistía o la prescripción que venden perdón por olvido. Debemos, por supuesto, pensar la interrupción de la culpa o de la pena sin que sea a costa del olvido.

3.3. La memoria abre expedientes que la ciencia da por archivados.

De la memoria se ocupa la filosofía, pero también la historia, el derecho y la política. Son miradas diferentes. La «ciencia histórica» tiene por objetivo contar los hechos si no como fueron al menos lo más parecido. Su afán explicativo no pretende hacer un juicio moral sobre lo ocurrido. La memoria, sí. Para la memoria, en efecto, las injusticias no son desigualdades, por eso habla de víctimas y verdugos o de responsabilidad histórica. Así se entiende lo que escribe García Márquez en Los funerales de la Mamá Grande cuando dice que hay que contar las cosas antes de que lleguen los contadores oficiales que vienen de fuera. Para los historiadores que se traen los conquistadores de Occidente, lo de antes de su llegada no tiene valor ni sentido. Es la prehistoria de la que hay que salir para entrar en la historia. Pero para los asistentes a los funerales de la Mamá Grande, ese pasado no es la prehistoria sino sus raíces que hay que salvar o contar para conjurar la peste del olvido que asola a Macondo, es decir, al Nuevo Mundo.

Tampoco se identifica con la «ciencia jurídica», especializada en identificar delitos, mientras que la memoria habla de culpas. El delito se mide por leyes que tabulan la gravedad de la acción y de las penas consecuentes. La culpa es un concepto moral que liga la conciencia del agente con el daño a la víctima. La culpa sobrevive al delito de suerte que sigue vigente aunque se haya cumplido el castigo previsto por la ley. Es la señal de Caín de la que habla el Génesis.

Tampoco se identifica con la «ciencia política» cuya política de la memoria poco tiene que ver con la memoria pública que aquí interesa. Aquélla, en efecto, está pensada en función de los ciudadanos presentes porque la política 
es de los vivos, mientras que la memoria pública está en función de los ausentes. Son dos perspectivas diferentes. Cabe imaginarse un archivo del caso por la historia (si el caso está bien explicado), por el derecho (si ha cumplido la pena) o por la política (cuando orienta el pasado en función de los intereses presentes), pero no por la memoria mientras no se haya reparado integralmente el daño causado.

3.4. La memoria permite rescatar el viejo concepto de justicia general.

Hoy domina en justicia el concepto de «justicia social», un tipo de justicia distributiva y, por tanto, particular, que no tiene el alcance del concepto antiguo de justicia general, prácticamente desaparecido. La justicia general estaba regida por el principio "pars et totum quodanmodo sunt idem», lo que equivale a decir, en primer lugar, que el bien común no existe al margen de las partes, como si cada parte llevara inscrita en su singularidad una dimensión comunitaria y, en segundo lugar, que hay algo más que las partes de suerte que cada parte está remitida a una dimensión superior. De acuerdo con este planteamiento, cada parte, para ser justa, tiene que desarrollar sus talentos, en tanto que todos los demás son responsables de crear las condiciones para el desarrollo de los talentos de cada cual. Habría entonces injusticia si uno no desarrolla los talentos o los demás no crean las condiciones del desarrollo.

Esta ambiciosa justicia general tenía, sin embargo, un deficit de universalidad, el mismo que arrastraba el concepto de virtud. El acto virtuoso estaba al servicio de la naturaleza de suerte que su recorrido no podía traspasar lo que dictara la naturaleza. Si, como en el caso de Aristóteles, el esclavo no participaba de la naturaleza humana, no tenía nada de vicioso tratarle inhumanamente. Al centrarse la virtud, por otro lado, en el acto humano, tenía poco oído para las dimensiones estructurales o incluso institucionales de la justicia.

Para los modernos uno de los momentos estructurales más importantes es el lenguaje. Walter Benjamin, por ejemplo, hace de él una de las encrucijadas decisivas de la justicia. En su teoría del lenguaje distingue el lenguaje adámico, anterior a la caída, y el postadámico que es el nuestro. Propio del primero era la adecuación del nombre a la esencia lingüística de lo nombra. El nombre que Adam daba a las cosas respondía al ser de las cosas. El hombre postadámico ha perdido ese poder. Lo único que ahora podemos es aproximarnos torpemente a las cosas a través de denominaciones que velan más que desvelan o revelan el ser de las cosas. Ahora las cosas se sienten injustamente nombradas.

Una justicia general, pensada en clave benjaminiana, tendría que ocuparse no sólo del bien común, sino de lo innombrado con nuestras palabras para «que nada se pierda», como él dice. Esta nueva forma de justicia estructural sólo puede ser negativa porque no se nos alcanza positivamente el ser lingüístico de las cosas o de los acontecimientos. 
Podríamos recurrir, para explicarlo, a la imagen del ánfora (que el propio Benjamin propone a propósito de la traducción)

«así como los trozos de un ánfora (rota), para que se pueda reconstruir el conjunto, han de ser contiguos en los más pequeños detalles, pero no idénticos unos a otros, así, en lugar de asemejarse al sentido original, la traducción debe, más bien, movida por el amor, y hasta en el detalle, hacer entrar en su propia lengua el modo de ver las cosas propio del original: de esta manera, igual que los trozos llegan a ser reconocibles como fragmentos de una misma ánfora, original y traducción llegan a ser reconoscibles como fragmentos de un lenguaje mayor» (GS IV 1 18).

Si sustituimos el término traducción por justicia tenemos que la justicia es como un ánfora rota cuya reconstrucción depende de que encontremos a cada parte su trozo correspondiente. Las partes no son iguales, como no lo son los trozos de un objeto roto. La justicia es el proceso impulsado por la parte ya localizada. La justicia general reside en el campo abierto o en la interpelación que nos dirige cada experiencia - cada trozo encontrado- de injusticia. Lo que la metáfora nos dice es que el ánfora está rota. No hay foto de archivo que sirva de modelo con el que guiarnos en la restauración de la obra. El ánfora es un proyecto que sólo se puede poner en marcha reconociendo a cada parte el carácter de fragmento, de trozo singular a la búsqueda de su complementario. La justicia no puede ser una teoría cerrada, no tiene un fin, sino que es un pro-yecto. Las partes rotas del ánfora aluden, por un lado, a esa historia passionis que subyace a cada singular, substrato que es ninguneado por la teoría general de la justicia, y, por otro, a los silencios subyacentes a toda palabra y que son declarados insignificantes por los discursos dominantes. Hablar de justicia es avanzar desde cada fragmento, buscando su correspondiente exacto.

3.5. Sin memoria la justicia global no puede ser universal.

La justicia global ha supuesto un gran avance en lo que podríamos llamar la universalidad espacial. Se han roto los límites territoriales que habían levantado los Estados y en su lugar aparece una justicia transterritorial. La posibilidad legal de que un juez español procese a un dictador chileno que paseaba por Londres, acusándole de crímenes contra la humanidad, ilustra bien su novedad e importancia.

Pero la grandeza de la justicia global es que no afecta sólo a asuntos tan graves como los crímenes de lesa humanidad, sino a algo tan cotidiano y poco épico como el hambre en el mundo o la pobreza que son catalogadas no como hechos productos del azar sino como injusticias. Thomas Pogge, uno de los teóricos más señalados de esta justicia, distingue entre el deber positivo de ayudar al necesitado y el deber negativo de combatir la injusticia. La justicia global está por el deber negativo porque estiman que la pobreza es injusta (Pogge, 2005, 252). Y lo es porque es inexplicable sin alguna de estas tres causas: en primer lugar, un orden institucional económico, 
diseñado por los más ricos, que produce inevitablemente la miseria. El neoliberalismo que ha presidido el despliegue actual del capitalismo a escala mundial no es neutro ni inocente. Busca la maximización de beneficios sin contemplaciones. En segundo lugar, la pobreza es el resultado de la exclusión forzada del acceso a los recursos naturales. Los países más ricos disponen de tecnología y financiación para la explotación de los recursos naturales situados en territorio de los países pobres. Es verdad que pagan por ello pero a las élites locales o desde unos supuestos tan ventajosos que resultan insuficientes (Pogge, 2005, 256). En tercer lugar, porque las profundas desigualdades actuales son resultado de una violenta historia común. Hay pues una relación entre la riqueza de los ricos y la pobreza de los pobres. La pobreza no es ni natural ni fruto del azar. Los pobres no nacen pobres sino que son empobrecidos.

Este planteamiento, hecho no desde ideologías izquierdistas sino desde el reconocimiento del derecho de los pobres, no se anda con remilgos. Considera la pobreza actual como un crimen contra la humanidad y si eso choca a alguien es, dice, porque no acaba de ver la relación causal entre nuestra riqueza y su pobreza.

Vistas así las cosas parecería que al ciudadano de los países ricos habría que pedirle cuentas no sólo de lo que pasa en Somalia sino de lo que hicieron los abuelos que conquistaron esas tierras en el pasado, es decir, habría que hablar de responsabilidad espacial y también de responsabilidad histórica. Pero aquí el defensor de la justicia global traza una línea roja y dice, tras afirmar que nuestra riqueza tiene que ver con su empobrecimiento, «esto no significa que debamos responsabilizarnos de los efectos más remotos de nuestras decisiones económicas» (Pogge, 2005, 253). ¿Por qué no? porque aunque podamos decir que «de aquellos polvos estos lodos», no podemos precisar en qué proporción somos responsables. Por supuesto que este mundo desigual es el resultado de una historia común, con el matiz de que unos heredan las fortunas y otros los infortunios pero, añade el autor contra toda lógica, «ello no equivale a decir (tampoco a negar) que los prósperos descendientes de quienes tomaron parte en esos crímenes tengan alguna obligación especial de indemnizar a los descendientes empobrecidos de quienes fueron las víctimas de tales crímenes» (Pogge, 2005, 257). No hay responsabilidad histórica. El famoso deber negativo se substancia en impedir que aquella desigualdad histórica se mantenga hoy. No hay que tocar la fortuna de los ricos, basta con imponerles un impuesto, el DGR (dividendo global de recursos). Dos dólares por barril de crudo.

Las responsabilidades no se heredan. Lo dice un pensador judío nacido después de Auschwitz.

Se entiende que Rawls descarte la responsabilidad histórica porque sus criterios de justicia son el resultado de un experimento atemporal, pero Tho- 
mas Pogge sólo puede seguir la estela del maestro si priva de significación teórica su laboriosa explicación histórica de la pobreza presente.

Si hay una relación causal entre la riqueza de los ricos y la pobreza de los pobres, es decir, si tomamos en serio la historia común como explicación de las desigualdades existentes, habría que tener el valor de seguir los pasos de Hermann Cohen cuando considera a la pobreza, y no la muerte, como el mal radical porque el ser humano es su causa y su solución. La pobreza es la experiencia radical y constante de la existencia humana a partir de la cual hay que pensar el ser humano. No somos iguales. Hay pobres y hay ricos o, mejor, hay pobres porque hay ricos. Esa diferencia no es antropológicamente neutral pues convierte a unos en «subhombres» y a otros en «superhombres», dos formas inhumanas de existencia. Nadie alcanza la humanidad por su cuenta. El pobre se hace humano en la medida en que el rico se des-enriquece y el rico se humaniza en la medida en que el pobre se des-empobrece. Esto no se arregla con un impuesto. Ese proceso sólo en posible si los sujetos actuales asumen su responsabilidad respecto a una desigualdad causada en el tiempo y que nos ha conformado tal y como somos hoy.

3.6. La memoria no es la justicia sino en inicio de un proceso justo cuyo final es la reconciliación.

La memoria no arregla nada sino que lo complica todo porque abre heridas. Puede y suele ser utilizada como atizador de la venganza, por eso, quien la invoque está obligado a pensarla hasta el final. Pensar consecuentemente la memoria es plantearse la justicia ad integrum aquí y ahora. Es una exigencia paradoxal porque el aquí y ahora de la justicia no garantiza la justicia integral. Excede las posibilidades de la existencia humana. La reconciliación sería la forma que toma la justicia absoluta en la modesta posibilidad del presente.

La memoria hace presente o se hace cargo de las injusticias pasadas, es decir, de los daños infligidos a un inocente. Es capital entonces la narrativa de los daños que no son siempre los mismos ni del mismo tipo. Los daños que sufre una víctima del terror difieren de los que sufre otra víctima de la velocidad, o del trabajo, o de la guerra o de los campos.

Tomemos como ejemplo las víctimas del terror Hay un daño personal (la muerte, el secuestro, la tortura, la amenaza, etc.); hay también un daño político (el asesinado es negado en su derecho a la ciudadanía. La bala asesina tiene un mensaje político: «no contáis para la sociedad por la que luchamos»); y hay finalmente un daño social (la sociedad atravesada por la violencia queda fracturada y empobrecida).

Hablar de la justicia referida la violencia política contemporánea, significa enfrentar ese triple daño. ¿Cómo hacer justicia, en primer lugar, al daño personal? La palabra clave es reparación: reparando lo reparable y haciendo memoria de lo irreparable. 
¿Qué significa, en segundo lugar, hacer justicia respecto al daño político? La palabra clave es reconocimiento efectivo del carácter ciudadano de la víctima. Pensemos en la violencia etarra. Es inexplicable sin el trasfondo de una ideología nacionalista que divide a los vascos entre los de verdad y los de fuera; entre los de aquí y los de allí, es decir, estamos alimentados por un nacionalismo que no asume la pluralidad de la sociedad vasca. El reconocimiento efectivo de la ciudadanía a las víctimas significa no renunciar al nacionalismo pero sí revisar al que es excluyente y ha sido la causa de la violencia terrorista.

Y ¿que significa, finalmente, reparar o hacer justicia al daño social, cómo restaurar la fractura de la sociedad, cómo re-enriquecer a esa sociedad empobrecida? La respuesta a esta pregunta consiste en recuperar para la sociedad a las víctimas y a los victimarios. A la víctima se la recupera a través del reconocimiento político al que me refería anteriormente. Respecto a la recuperación de los victimarios, el problema es cómo hacerlo. La reconciliación es imposible sin el perdón que es gratuito, por parte de la víctima, pero no se da gratis: conlleva el reconocimiento de un daño hecho a un inocente y la voluntad de enfrentarse a su violencia pasada para poder construir ahora la política sin violencia. En este itinerario se ve cómo la memoria pone ante los ojos de la sociedad la crudeza de la injusticia exigiendo en cada momento la respuesta adecuada que unas veces toma la forma de reparación y otras, memoria de lo irreparable. La reconciliación se trenza en ese proceso.

3.7. El gesto intelectual de Las Casas.

El gesto se fragua en Junta de Valladolid, años 1550 y 1551, en la que Bartolomé de Las Casas y Ginés de Sepúlveda disputan sobre los títulos de la conquista. El primero, que sabe lo que está ocurriendo, los niega; el segundo, gran humanista que no salido de sus libros en España, los defiende.

Las Casas recurre a los saberes teológicos y jurídicos que comparte con su adversario, para negar la validez los títulos de la conquista que el otro alega: el alcance de la autoridad papal y de la potestas del emperador, si los indios tienen capacidad para gobernarse, si se puede hablar de una superioridad de la cultura occidental, si la racionalidad de los indios es de inferior calidad que la de los españoles, si hay seres nacidos para obedecer y otros para mandar... Uno por uno va desmontando los argumentos contrarios y llevando el agua a su molino.

Hasta que el oponente se saca un arma letal que le paraliza: los sacrificios humanos, razón principal, invocada por Sepúlveda para justificar la guerra contra los indios. Este argumento que convoca la solidaridad humana tiene un enorme peso porque es compartido por muchos, hasta por el propio Vitoria que ve en esa práctica una «una injuria hecha a otros», algo así como un crimen contra la humanidad. Esa práctica obliga a la Iglesia a intervenir y también a los príncipes cristianos. 
Las Casas lo tiene difícil: por un lado está su experiencia, lo que él ha visto, esto es, la presencia opresora e injusta de los conquistadores. Por otro, el saber de Salamanca, la sabiduría de su tiempo, que legitima esa presencia con lo que se consolida la injusticia que él denuncia. La situación del indio ya es insostenible pero si se llega a legitimar ese estado de cosas, la catástrofe está asegurada. La razón dominante se opone a su sentimiento moral y a la evidencia de la experiencia. ¿Qué hacer?

Es en ese momento cuando tiene lugar el gesto intelectual de Las Casas que le obliga a traspasar y transgredir los venerables saberes establecidos, en virtud de la experiencia de la injusticia, en nombre del sufrimiento de las víctimas de la conquista y de la colonización. Lo primero es la experiencia de la injusticia y si los saberes establecidos proponen interpretaciones de los hechos que en vez de solucionar la injusticia la agravan, habrá que «mandar a Aristóteles a paseo» (Las Casas, 1975, 3), es decir, habría que declarar irracional a la racionalidad canónica. Si hay un conocimiento que legitime la injusticia o que encubra la evidencia, habrá que ponerla entre paréntesis y esforzarse por pensar a partir de esa situación injusta y no a partir de lo que digan los doctores.

El gesto de mandar a paseo a Aristóteles, tiene que ver con la reflexión que hace Borowski, un filósofo polaco deportado en Auschwitz: «Me acuerdo de cómo me gustaba Platón. Hoy sé que mentía». Y explica por qué mentía Platón: porque rebajaba este mundo de los hombres a sombra o apariencia, concediendo la densidad de la realidad al mundo de las ideas, cuando ha sido las lágrimas y la sangre del hombre las que engrasado las ruedas de la historia. Y concluye: «No hay belleza si está basada en el sufrimiento humano. No puede haber una verdad que silencie el dolor ajeno. No puede llamarse bondad a lo que permite que otros sientan dolor» (Borowski, 2004).

La verdad no es imparcial, ni impasible, tampoco partisana. «Hacer hablar al sufrimiento es la condición de toda verdad», dice Adorno. Y eso vale para la filosofía sobre todo cuando habla de justicia.

\section{BIBLIOGRAFÍA}

AA.VV. (2008): El perdón, virtud política, Anthropos, Barcelona.

Adorno, Th. (1966): Negative Dialektik, Suhrkamp (Dialéctica Negativa, Taurus Madrid).

Agamben (1999): Ce qui reste d'Auschwitz, Payot-Rivages, Paris.

BensaïD, D. (2007): Les depossédés. Karl Marx, les voleurs des bois et le droit des pauvres, La Fabrique, Paris.

Borowski, T. (2004): Nuestro hogar es Auschwitz, Alba Editorial, Barcelona.

CORTÉs, F. (2007): Justicia y exclusión, Siglo del Hombre Editores, Bogotá.

CORTÉs, F. (2009): De la política de la libertad a la política de la igualdad, Siglo del Hombre Editores, Bogotá. 
Cousin, V. (1992): Cours de philosophie. Introduction à la philosophie de l'histoire de 1828, Paris, Fayard.

DerAthÉ, R. (1995): J.J. Rousseau et la science politique de son temps, J. Vrin, Paris.

GonzÁlez, J. M. (2006): La diosa fortuna. Metamorfosis de una metáfora política, Antonio Machado Libros, Madrid.

Gradowski, Z. (2001): Au coeur de l'enfer, Editions Kimé (En el corazón del infierno, Anthropos, Barcelona 2008).

Guariglia, O. (2010): En camino de una justicia global, Marcial Pons.

HABERMAS: En «Treffen Hegels Einwände gegen Kant auch auf die Diskursethik zu?», cf. Kuhlemann, W. (Hrsg) (1986): Moralität und Sittlichkeit, Suhrkamp, Frankfurt.

Habermas (1991): «Justicia y solidaridad», en K. O. ApPel, A. CortinA, J. DE Zen y D. Michelin (eds.), Ética comunicativa y democracia, Editorial Crítica, Barcelona.

HABERMAS (2010): «La vie bonne, une expression detestable. La signification de l'éthique religieuse du jeune Rawls pour sa théorie politique», en RAWLS, J., 2010, Le péché et la foi. Ecrits sur la religion, Hermann, Paris, 351-377.

JüNGER, E. (1990): L'Etat universel suivi de La mobilisation totale, Gallimard, Paris.

Kovadloff, S. (1996): Lo irremediable. Moisés y el espíritu trágico del judaísmo, Emecé, Buenos Aires.

Las CASAs, B. (1975): Apología, Editora Nacional, Madrid.

LE Goff, J. (1988): Histoire et mémoire, Gallimard, Paris.

LEvi, P. (1989): Los hundidos y los salvados, Muchnik, Barcelona.

McIntyre, A. (1987): Tras la virtud, Crítica, Barcelona.

MuguerzA, J. (1989): «La alternativa del disenso», en Muguerza y otros (eds.), El fundamento de los derechos humanos, Editorial Debate, Madrid, 19-57.

Pogge, Th. (2005): La pobreza en el mundo y los derechos humanos, Paidós, Barcelona.

Nino, C. (1996): «Justicia», en E. GARZÓN VALdÉS y F. LAPORTA (eds.), Justicia y Derecho, Eiaf, Trotta, Madrid.

Rawls, J. (1978): Teoría de la justicia, FCE, México.

Rawls, J. (2010): Le péché et la foi. Ecrits sur la religion, Hermann, Paris.

Rousseau (1964): Oeuvres Complètes, III, Pléiade, Paris.

SEMPrún, J. (1995): La Escritura o la Vida, Tusquets, Barcelona.

SEn, A. (2010): La idea de la justicia, Taurus, Madrid.

Steiner, G. (1973): Dans le Château de Barbe-Bleu, Seuil, Paris.

SucAsas, A. (2002): Memoria de la Ley, Ríopiedras, Barcelona.

SuCASAS, A. (2010): «Entre escritura e historia: el tiempo en la experiencia judía», en

Sucasas-Zamora, Memoria-política-justicia. En diálogo con Reyes Mate, Trotta, Madrid, 261-275.

Taubes, J. (1996): Vom Kult zur Kultur (en el apartado «Zur Konjuntur des Polimythismus»), Fink Verlag, München.

VAn PARIJs (1992): ¿Qué es una sociedad justa?, Ariel, Barcelona.

Wiesel, E. (1961): Le Jour, Seuil, Paris. 